\title{
Devolatilization and Ignition of Coal Particles in a Two-Dimensional Fluidized Bed
}

\author{
W. PRINS, R. SIEMONS, and W. P. M. VAN SWAAIJ \\ Mechanical and Chemical Engineering Departments, University of Twente, Enschede, The Netherlands
}

and

M. RADOVANOVIC

Masinski Fakultet, Beograd, Yugoslavia

\begin{abstract}
In a two-dimensional $(15 \times 200 \times 400 \mathrm{~mm})$ high-temperature fluidized bed, devolatilization ignition and combustion phenomena of single coal particles have been studied. The particles, with diameters of 4-9 $\mathrm{mm}$, were selected from three coal types of widely different rank: brown coal, bituminous coal, and anthracite. The bed consisted in most cases of porous alumina particles $\left(0.6 \mathrm{~mm}\right.$ diameter), and was fluidized by $\mathrm{O}_{2} / \mathrm{N}_{2}$ gas mixtures. At constant bed temperatures ranging from 200 to $850^{\circ} \mathrm{C}$. the various stages prior to the eventual combustion of the residual char particle were recorded on videotape. This paper gives an account of visual observations on the release, ignition, and combustion of volatiles as well as on the ignition of char. Results of measurements of the temperature and delay time of both volatiles and char ignition are also reported. Finally, the period over which flames of volatiles are visible in the bed has been measured for each coal particle; at sufficiently high bed temperature they are indicative for the total devolatilization time.
\end{abstract}

\section{NOMENCLATURE}

Ar

$g d_{p}{ }^{3} \rho_{p} / \rho_{g} \nu_{g}{ }^{2}$, Archimedes number (dimensionless)

$\mathrm{Bi} h d / 2 \lambda$, Biot number (dimensionless)

$c_{\text {fix }}$ fixed carbon content of the coal (dry basis) (wt \%)

$c_{p} \quad$ specific heat of the coal $\left(\mathrm{J} / \mathrm{kg}^{\circ} \mathrm{C}\right)$

$d$ coal particle diameter (m)

d average coal particle diameter (m)

$d_{p} \quad$ diameter of the bed particles (m)

Fo $\quad 4 \alpha t / d^{2}$, Fourier number (dimensionless)

$f_{T}$ temperature correction factor (dimensionless)

$g$ acceleration due to gravity $\left(\mathrm{m} / \mathrm{s}^{2}\right)$

$H$ heat of formation, combustion, evaporation $(\mathrm{J} / \mathrm{mol})$ $h$ coefficient of heat transfer to the coal particle $\left(\mathrm{J} / \mathrm{s} \mathrm{m}^{2}{ }^{\circ} \mathrm{C}\right)$

$h_{\max }$ maximum coefficient of heat transfer to the coal particle $\left(\mathrm{J} / \mathrm{s} \mathrm{m}^{2 \circ} \mathrm{C}\right)$

$n$ diameter exponent in relationship between volatiles burn-out time and coal particle diameter (dimensionless)

$n \quad$ exponent of Archimedes number in Eq. 2 (dimensionless)

$\mathrm{Nu} h d / \lambda_{g}$, Nusselt number based on carbon particle diameter (dimensionless)

$\mathrm{Nu}_{\max } h_{\max } d_{p} / \lambda_{g}$, maximum Nusselt number based on bed particle diameter (dimensionless)

$r \quad$ distance from the coal particle center (m)

$T$ temperature $\left({ }^{\circ} \mathrm{C}\right)$

$T_{b} \quad$ bed temperature $\left({ }^{\circ} \mathrm{C}\right)$

Copyright $(\mathcal{C} 1989$ by The Combustion Institute 
$T_{c} \quad$ coal particle center temperature $\left({ }^{\circ} \mathrm{C}\right)$

$T_{c i} \quad$ char ignition temperature $\left({ }^{\circ} \mathrm{C}\right)$

$T_{v i} \quad$ volatiles ignition temperature $\left({ }^{\circ} \mathrm{C}\right)$

$T_{o}$ original coal particle temperature $\left({ }^{\circ} \mathrm{C}\right)$

$t$ time (s)

$t_{c i} \quad$ char ignition delay (s)

$t_{h} \quad$ heating time of the coal particle (s)

$t_{v i} \quad$ volatiles ignition delay (s)

$t_{v e} \quad$ flame extinction time (s)

$U_{b} \quad$ bubble velocity $(\mathrm{m} / \mathrm{s})$

$U$ fluidization velocity $(\mathrm{m} / \mathrm{s})$

$U_{m f} \quad$ minimum fluidization velocity $(\mathrm{m} / \mathrm{s})$

$V M$ volatile matter content of the coal (dry basis) (wt\%)

$X_{0_{2}} \quad$ oxygen mole fraction (dimensionless)

$\alpha \quad \lambda / \rho c_{p}$, thermal diffusivity of the coal $\left(\mathrm{m}^{2} /\right.$ s)

$\epsilon_{m f}$ bed porosity at minimum fluidization conditions (dimensionless)

$\lambda$ thermal conductivity of the $\operatorname{coal}(\mathrm{J} / \mathrm{s}$ $\mathrm{m}^{\circ} \mathrm{C}$ )

$\lambda_{g}$ thermal conductivity of the gas $\left(\mathrm{J} / \mathrm{s} \mathrm{m}^{\circ} \mathrm{C}\right)$

$\nu_{g} \quad$ kinematic viscosity of the gas $\left(\mathrm{m}^{2} / \mathrm{s}\right)$

$\rho$ coal density $\left(\mathrm{kg} / \mathrm{m}^{3}\right)$

$\rho_{g} \quad$ density of the fluidizing gas $\left(\mathrm{kg} / \mathrm{m}^{3}\right)$

$\rho_{p} \quad$ bed particle density $\left(\mathrm{kg} / \mathrm{m}^{3}\right)$

\section{INTRODUCTION}

When coal particles are introduced into a fluidized bed combustor, whether by in-bed or over-bed feeding, they first start to dry and devolatilize; this is followed by the ignition and combustion of volatiles and the residual char. Volatiles' combustion may occur in the freeboard or in the fluidized bed depending on the coal supply system, the original volatile matter content of the coal, and the rate of devolatilization. For the design and operation of a fluidized bed combustor the location and rate of volatiles release and combustion is very important; volatiles may produce up to $50 \%$ of the total heat released in the combustor. If the combustion of volatiles takes place in the freeboard it will contribute considerably to the freeboard excess temperature. Freeboard temperatures are related to the levels of polluting $\mathrm{NO}_{\mathrm{x}}$ and $\mathrm{SO}_{2}$ emissions. The pattern of volatiles evolution and combustion in the bed is also important in connection with the occurrence of possible reducing zones [1-3]. Another phenomenon important for fluidized bed combustor design and operation is the ignition of solid fuel. Knowledge of the lowest bed temperature required for the ignition of residual char particles and the corresponding delay time is necessary for the optimization of start-up and dynamic control procedures.

Traditionally there are two methods for the determination of devolatilization and ignition properties of fuels, at constant temperature or at constant heating rate. In a fluidized bed combustor, however, cold coal particles are introduced into a large heat reservoir of constant temperature. During devolatilization and ignition the coal particle temperature changes from room to bed temperature. Consequently the heating rate of the coal particle is also changing continuously. Devolatilization and ignition phenomena strongly depend on the coal particle heating rate. In addition to the heat, mass transport parameters may also affect these phenomena. It is quite difficult to predict the combined effect of heat and mass transfer in a fluidized bed and simulate the coal particle behavior. Therefore, in the present investigation experiments are carried out in a two-dimensional hot flow model of a fluidized bed for a range of important practical situations. A coal particle introduced in such a construction can be directly and continuously observed. In this way many important phenomena can be described accurately. The study considers the various stages from the moment of the introduction of the coal particles until the burn out of residual char is well under way. Burn-out times of char particles are not reported; the combustion of carbon particles in a fluidized bed was subject of a special study and is treated elsewhere [4].

\section{PREVIOUS WORK}

When considering devolatilization phenomena, one should distinguish between oxidizing and inert conditions. The simultaneous combustion of volatiles may well affect their escape from the coal particle.

For oxidizing conditions, the volatiles burn-out 
time, as determined by establishing the moment of flame extinction, has often been interpreted as an indication of the devolatilization time. By comparison of various data from literature this can shown to be a questionable approach. Published results for oxidizing conditions report on the volatiles burn-out time as a function of the fluidized bed temperature $[5,6]$, the fluidizing velocity [6], the coal particle or sample size [5-7], and the type of coal [5, 6]. Flint et al. [6] found that the volatiles burn-out time, as observed from bed surface flames, decreases with increasing bed temperature for the range $700<T_{b}<925^{\circ} \mathrm{C}$, and that the fluidizing velocity has hardly any effect. Pillai [5] investigated the influence of the coal particle diameter. While assuming the volatiles burn-out time in the fluidized bed to be proportional to $d^{n}$, he found values of $n$ ranging from 0.3 to 1.8 for increasing bed temperatures and various coal types. Ragland et al. [8] reported $n=1.5$ at $T_{b}=$ $850^{\circ} \mathrm{C}$ independent of coal type and oxygen mole fraction in the bed.

For inert conditions devolatilization times can directly be measured by analyzing the exit gas stream of a nitrogen fluidized bed, as the time corresponding to evolution of, for example, $95 \%$ of the total gas yield [9]. La Nauze [7] concluded from data on devolatilization of various coal types in the absence of combustion that the devolatilization time is proportional to $d^{2}$ and ascribed this to an internal diffusion controlled evolution mechanism. This differs from Pillai's results [5] for the influence of coal particle size on the volatiles burn-out time obtained at oxidizing conditions. Moreover, the devolatilization times of single coal particles measured by Stubington and Sumaryono [9] are considerably larger than the volatiles burnout times obtained by Pillai [5] and those reported by Ragland et al. [8].

As a consequence of differences in the applied experimental technique (using batches or single coal particles, for example) and conditions (oxidizing or nonoxidizing), as well as differences in observation technique (flame behavior or gas analysis), results of fluidized bed devolatilization do not lead to consensus. Theoretical modeling may be helpful with respect to the performance of proper experimental studies. A proposal for a simple model of devolatilization in a fluidized bed under the absence of combustion was made by Agarwal et al. [10]. This model combines the devolatilization kinetics as derived by Anthony et al. [11] with the processes of heat transfer through and to the coal particle. The general model developed by Bliek [12] is based on a fundamental description of intraparticle mass transfer (Dusty Gas flux equations), intraparticle heat transfer, and lumped kinetic expressions for devolatilization and tar deposition. Coal type, coal particle size, and heating rate were used as model parameters. Both models mentioned here predict a kinetically controlled devolatilization rate for small coal particles and a heat transfer controlled regime for large particles at typical fluidized bed combustor conditions. Agarwal et al. [10] also based their conclusion of a heat transfer controlled devolatilization mechanism for particles larger than $1 \mathrm{~mm}$ diameter on a presupposed square power proportionality of the devolatilization time with the coal particle diameter. In a recent article however [13], Agarwal recognized the fact that this $d^{2}$ law is only applicable to fluidized bed combustor conditions for certain extreme situations (such as for external heat transfer controlled devolatilization with $\mathrm{Nu}=2$ ). Stubington and Sumaryono [9] assessed the importance of heat transfer for the overall rate of devolatilization by calculating coal particle heating times and comparing them with the experimentally determined devolatilization times. In the Appendix similar heat transfer calculations, but with the improved data from Prins et al. [14], are carried out to estimate coal particle heating times for comparison with the present experimentally observed flame extinction times. An analysis of the Appendix provides a new relationship between the fluidized bed heating time of a coal particle and its diameter.

The above mentioned recent work of Agarwal [13] focused on the effect of subsequent combustion of volatiles on the devolatilization rate. The description of the heat flow from a surrounding volatile flame to the coal particle has been added to the model formulation. As a consequence the calculated devolatilization rate would be increased because of the higher particle temperature. Agarwal also discussed the applicability of his 
model for fluidized bed combustion. While referring to the work done by Cowley and Roberts [15] and Dennis et al. [16], he suggested that volatiles combustion predominantly occurs within bubbles. This was accounted for by the introduction of phase residence time factors. The present investigation will also provide experimental evidence for the location of volatiles combustion. Our experimental technique may be suited for the determination of values for the phase residence time factors. Finally, Agarwal's model predictions for burn-out times of large coal particles will be compared to the experimental results of the present study.

Many studies about fluidized bed devolatilization [17-19] and coal/char combustion [4, 20, 21] are available. Little has been reported on the ignition of volatiles and coal/char in a fluidized bed, except for our previous paper [22]. Apart from the attention paid to the evolution and combustion of volatiles, the latter phenomena will therefore also be elucidated here by careful observations and some relevant measurements that are made possible by our two-dimensional hot flow fluidized bed model.

\section{EXPERIMENTAL SET-UP AND CONDITIONS}

The construction of the two-dimensional quartz bed was instigated by the desirability of observing the coal particle directly in its fluidized bed environment. In cylindrical beds, as used in previous research, flames of volatiles arising from the bed surface are the only possible indication of volatiles ignition and extinction. Flames located in the bed's interior cannot be taken into account. Moreover the two-dimensional bed allows the use of a single coal particle. Averaged results obtained by repeating the single particle experiment several times provide more information (e.g., in view of comparison with single particle model predictions) than those obtained by simultaneous combustion of many particles in a batch. In addition, the oxygen mole fraction in the bed will remain constant in the single particle experiments and can be precisely adjusted. For accurate observations and measurements on the various other phenomena such as particle fracture, mixing, and heterogeneous ignition, the two-dimensional construction also appears to be a very useful instrument.

A general view of the experimental set up is given in Fig. 1. The construction of a twodimensional transparent fluidized bed to be operated at high temperatures is quite difficult. Due to expansion, each connection or coupling in such a construction can easily become damaged on heating. Therefore each part of the bed is made of quartz (low expansion coefficient) and is carefully polished to ensure a tight fit. An adhesive called Autostatic (Carlton Brown and Partners Ltd.,

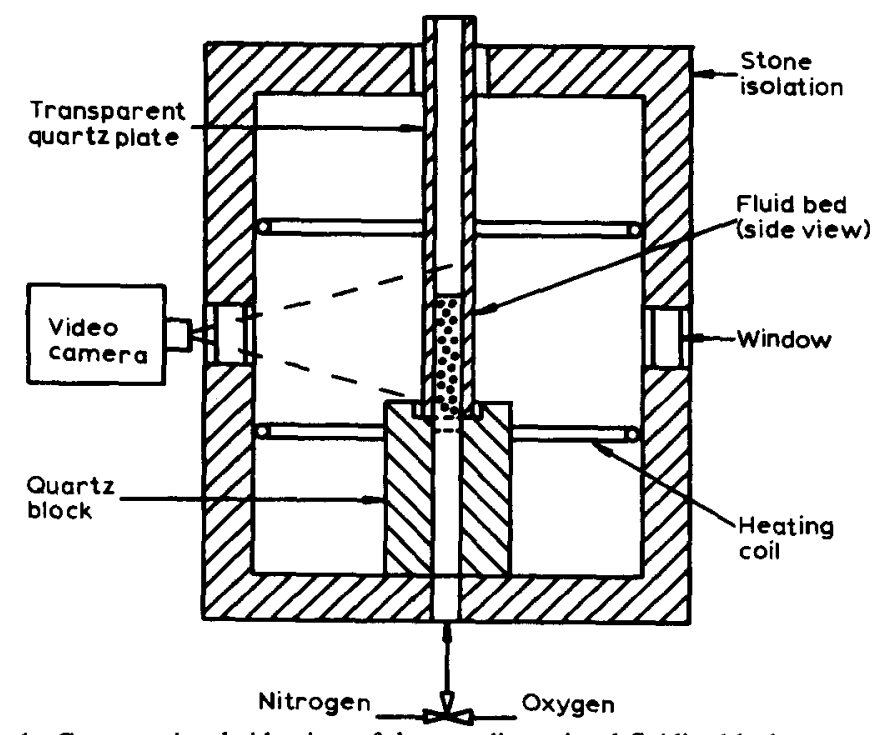

Fig. 1. Cross-sectional side view of the two-dimensional fluidized bed construction. 
U.K.) was used to bond all parts. To allow repolishing of the fluidized bed walls, the adhesive can be removed by boiling the apparatus in water for about 48 hours. The outer dimensions of the bed are $27 \times 200 \times 400 \mathrm{~mm}$ and the inner distance between the two bed walls, made of highly transparent quartz plates of $6 \mathrm{~mm}$ thickness, is $15 \mathrm{~mm}$. Avoiding too much interference with the walls, the use of (nonswelling) coal particles up to $9 \mathrm{~mm}$ diameter is now allowed. To stabilize the construction, the bed has been placed upon a heavy quartz block. A gas tunnel through this block terminates into a small wind box covered with a grid of fused quartz particles. The entire apparatus is placed into an electric furnace that enables independent temperature control up to $1000^{\circ} \mathrm{C}$. The top of the fluidized bed unit extends into an opening through the cover of the furnace, where coal particles can be supplied to the bed. Two heat-reflecting gold-coated quartz windows in the furnce wall are mounted in front of each side of the two-dimensional bed. Ignition and combustion processes can now be observed in reflected light, transmitted light, or the bed's own radiation, depending on the conditions and objectives of the measurements. Simultaneous recording by T.V. video enables accurate analysis of the obtained data by slow-motion and freeze-frame techniques.

Two different inert bed materials were used,
$600 \mu \mathrm{m}$ porous alumina spheres $\left(\rho_{p}=1800 \mathrm{~kg} /\right.$ $\mathrm{m}^{3}$ ), and, occasionally, $500 \mu \mathrm{m}$ dense alumina spheres $\left(\rho_{p}=3800 \mathrm{~kg} / \mathrm{m}^{3}\right)$. Selection of the bed material was based on preliminary coal mixing experiments. The expanded bed height was 110 mm. For both bed materials the minimum fluidization velocities have been measured as a function of the bed temperature (see Fig. 2). They appeared to differ by about a factor 2 over the applied temperature range. Consequently, coefficients of heat and mass transfer between bed and coal particle slightly differ for the two bed materials $[14,23]$. The fluidizing gas was composed of oxygen and nitrogen; the oxygen mole fraction and fluidizing velocity could be adjusted by changing the pressure difference over critical flow orifices. Coal samples were taken from a series of some 100 particles originally belonging to a single lump of coal. Each particle sample has been modeled by tweezers to an approximately spherical shape. Particle densities were measured, and those with a considerably different value from the average were removed.

\section{RESULTS}

At constant bed temperatures ranging from 200 to $850^{\circ} \mathrm{C}$ the following phenomena were investigated: volatiles ignition delay; location and mani-

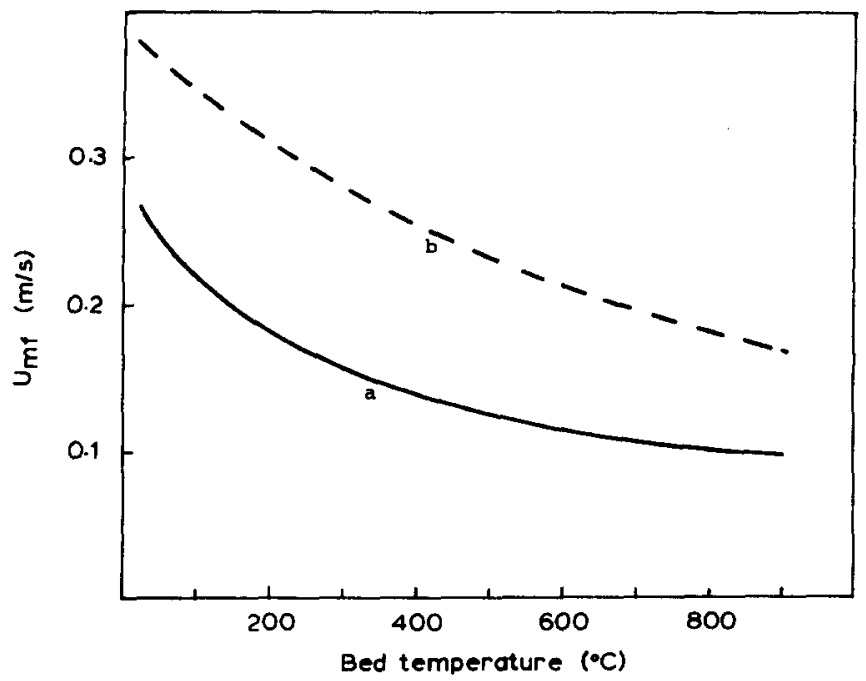

Fig. 2. Minimum fluidization velocity as a function of the bed temperature for the two different bed materials: a, $500 \mu \mathrm{m}$ low-density alumina spheres, $\rho_{p}=1800 \mathrm{~kg} / \mathrm{m}^{3} ; \mathrm{b}$, $600 \mu \mathrm{m}$ high-density alumina spheres, $\rho_{p}=3800 \mathrm{~kg} / \mathrm{m}^{3}$. 
festation of volatile flames; flame period of volatiles and flame extinction times; char ignition of partially devolatilized coal particles; lowest bed temperature for volatiles ignition; and lowest bed temperature for char ignition of partially devolatilized coal particles.

The experimental program involved the variation of bed temperature, fluidization velocity ( $U$ - $U_{m f}=0.25$ and $0.5 \mathrm{~m} / \mathrm{s}$ ), oxygen mole fraction (0.05-0.025), coal particle diameter (4-9 $\mathrm{mm})$, and coal type. It was decided to keep the fluidization velocity at constant $U-U_{m f}$ over the range of bed temperatures to realize equal bubble hold-up and bed turbulence. Basically, four coal types (Table 1) have been studied: lignite, brown coal, bituminous coal, and anthracite (4). The difference between the particles of coal type $2 *$ and 2 is in the moisture content. Type $2^{*}$ coal particles are wet (as received) and contain $48.5 \%$ moisture. Type 2 particles are (like all other coal samples) air dried at ambient conditions for at least 16 hours; they contain $16.4 \%$ moisture. Volatiles evolution, ignition, and combustion processes were separated from the ignition of residual char by comparing results of measurements on coal type 3 particles to those obtained for char particles $3^{*}$ derived from the same coal type. That char was prepared in a cylindrical bed fluidized by nitrogen gas at $850^{\circ} \mathrm{C}$.

\section{OBSERVATIONS}

The photographs in Fig. 3, which are copies of video pictures, illustrate what can be seen in the two-dimensional bed. They show a bituminous coal particle ( $9 \mathrm{~mm}$ diameter) in its fluidized bed environment at $800^{\circ} \mathrm{C}$, approximately 20 seconds after its introduction into the bed. The white areas of the photos represent the bed material, consisting of white alumina spheres $(500 \mu \mathrm{m}$ diameter and $3800 \mathrm{~kg} / \mathrm{m}^{3}$ particle density) that highly reflect the light provided from an external source. At the applied fluidizing velocity of around $1 \mathrm{~m} / \mathrm{s}$ the bed turbulence is rather high. The bubble phase, which transmits the light from the glowing heating coils of the furnace, can be recognized as the (darkish) red areas. Flames of volatiles released from the coal particle are visible in the bubble phase. The black areas are formed by the coal particle and its surrounding cloud of soot, tails of which arise in the bed by the cracking of tarry components released from the coal particle. The coal particle is not visible in Fig. 3b (the photo shows no black area) and must therefore have been located against

TABLE 1

Coal Analyses

\begin{tabular}{|c|c|c|c|c|c|c|}
\hline & 1 & 2 & $2 *$ & 3 & $3 *$ & 4 \\
\hline \multicolumn{7}{|l|}{ Proximate Analysis (\%) } \\
\hline Moisture & 12.6 & 16.4 & 48.5 & 1.9 & 0 & 1.3 \\
\hline Volatile Matter & 48.0 & 33.9 & 20.9 & 35.3 & 0 & 11.3 \\
\hline Ash & 4.1 & 24.0 & 14.8 & 19.2 & 30.5 & 4.6 \\
\hline Fixed Carbon (by difference) & 35.3 & 25.6 & 15.8 & 43.7 & 69.5 & 82.7 \\
\hline \multicolumn{7}{|l|}{ Ultimate Analysis (\%) } \\
\hline Carbon & 65.6 & 39.9 & 24.6 & 64.9 & 80.6 & 87.4 \\
\hline Hydrogen & 3.9 & 3.8 & 2.3 & 3.4 & 5.4 & 3.8 \\
\hline Nitrogen & 0.7 & - & - & 0.9 & 1.6 & 0.9 \\
\hline Sulphur & 0.2 & 1.0 & 0.6 & 0.8 & 0.7 & 0.3 \\
\hline Oxygen & 12.8 & 14.9 & 9.2 & 9.0 & 5.6 & - \\
\hline Chlorine & 0.1 & - & - & 0.1 & 0.2 & 0.1 \\
\hline
\end{tabular}

2* Wet brown coal, type 2 as received.

$3^{*}$ Char of type 3 , prepared in a nitrogen fluidized bed at $850^{\circ} \mathrm{C}$. 

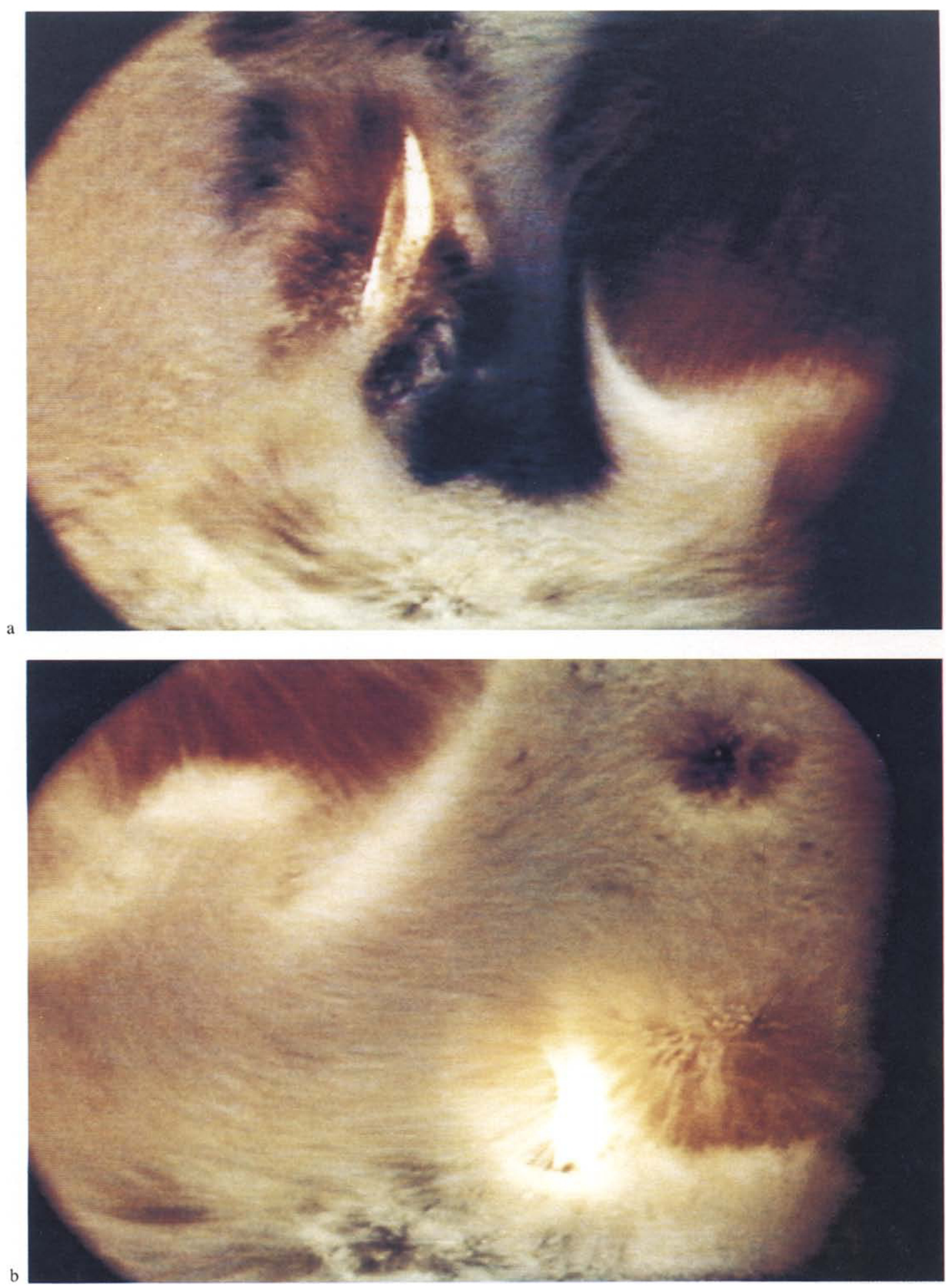

Fig. 3 Frontal view of the two-dimensional fluidized bed through one of the quartz windows in the furnace wall; $T_{b}=850^{\circ} \mathrm{C}$; $a$, tar and volatiles releasing coal particle during the first stage of the flame period; $b$, volatiles releasing coal particle during the last stage of the flame period. (Scale 2:1) 
the back wall of the fluidized bed at the time the picture was taken. It should then be observed through the window of the opposite furnace wall (see Fig. 1). Figure 3 clearly shows the capability of the two-dimensional hot flow set-up to provide precise information on the coal particle behavior under fluidized bed combustor conditions. Detailed observations are summarized below.

\section{Coal Particle Fracture}

The first thing that can happen after the introduction into the fluidized bed is the splitting or fracturing of the coal particle into several smaller particles. This phenomenon appeared to depend strongly on coal type. Anthracite coal particles split into tens of smaller particles, while the brown coal particles remain unbroken. Particle fracture may be caused by both thermal shock and pressure build-up inside the coal particle due to the liberation of pyrolysis products. For highly volatile bituminous coal particles of 1-10 mm diameter, Bliek [12] calculated maximum overpressures at the particle center of 1-3 MPa upon heating at a rate of $50^{\circ} \mathrm{C} / \mathrm{s}$. (This value of the heating rate is typical for fluidized bed combustors; see Appendix). High rank coals contain less volatiles. However, considering their brittle structure, the intraparticle overpressures arising during devolatilization may be high enough to cause particle fracture.

\section{Tar Release}

The production of tarry components is visible during the devolatilization process by the appearance of black soot tails around the coal particle, mainly for the bituminous coal, and, to a lesser extent, for anthracite.

\section{Coal Particle Mixing}

Coal particles tend to float and remain in the upper part of the bed during devolatilization [5]. In the following period of char combustion the vertical mobility of the particle becomes better. Mixing of coal particles with a fluidized bed depends on coal particle size and density together with the bed particle size and density and the fluidization velocity [24]. In the present investigation the difference between the apparent density of the fluidized bed emulsion phase $\left(1150 \mathrm{~kg} / \mathrm{m}^{3}\right)$ and the particle density of the various coal samples $\left(1100-1450 \mathrm{~kg} / \mathrm{m}^{3}\right)$ was generally too small to allow observation of any effect of differences in type and size of coal particles on the mixing behavior for the fixed fluidization conditions. However, the many small particles born at the fracturing of the anthracite sample appeared to become well mixed over the entire bed volume immediately after their genesis. In addition, the positive effect of increased circulation of solids, induced by a higher fluidization velocity, was indeed observed in the occasional experiment with a bed of high-density alumina particles (emulsion phase density: $2300 \mathrm{~kg} / \mathrm{m}^{3}$ ). While fluidizing at two different gas velocities ( $U-U_{m f}=0.25$ and $0.50 \mathrm{~m} / \mathrm{s}$ ), the mixing of coal type 3 particles (density: $1420 \mathrm{~kg} / \mathrm{m}^{3}$ ) turned out to be much improved at the higher fluidization velocity.

\section{Volatile Flames}

At bed temperatures high enough for ignition and combustion of volatiles, the attendant volatile flames can be seen. Depending on the momentary location of the coal particle, they are of different natures (see Fig. 4):

Above the bed surface they appear as a yellow diffusion flame at the coal particle surface.

Within the bubbles interior they show as a yellow diffusion flame at the coal particle surface.

Occasionally at the bed surface they appear as a smaller blue, premixed flame, straight above but apart from the coal particle that is then situated several centimeters below the bed surface in the emulsion phase.

Volatile flames have not been observed in the dense phase of the fluidized bed. To explain this we suggest the following consideration. Although the heat transfer from the dense phase gas to the bed particles is sufficiently fast, the total heat capacity of the highly concentrated bed particles can be so large that a local flame formation is prevented. Such a heat sink is not present within bubbles. In addition, there is sufficient oxygen available to allow for the existence of a volatiles diffusion flame. With respect to this, it should be 

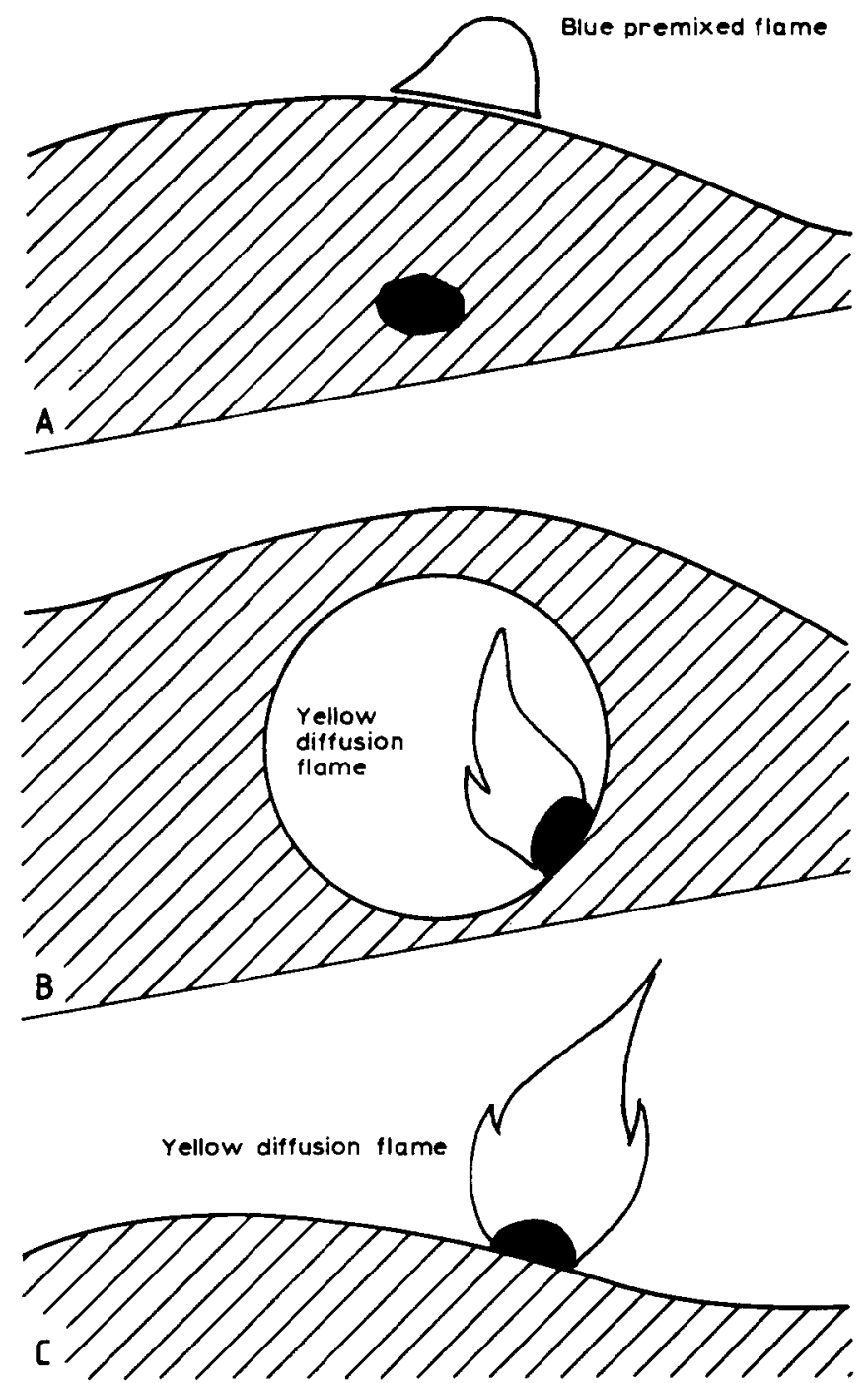

Fig. 4. Location and type of volatile flames: $A$, coal particle in emulsion phase; $B$, coal particle inside a bubble; $\mathrm{C}$, coal particle at the bed surface.

noted that bubbles are in the slow regime for fluidized bed combustor conditions in general as well as for our small-scale unit [25]. Combustion of volatiles in the dense phase of the fluidized bed is further suggested to be unlikely [16] in view of free radical quenching at the surface of bed particles. The preference of volatiles combustion to occur within bubbles or at the bed surface (in the splash zone) has already been recognized by Cowley and Roberts [15]. In a paper on the mechanism of $\mathrm{NO}_{x}$ generation in fluidized bed combustors, they also reported on a video study of the events of volatiles and char combustion, but in a cylindrical (145 $\mathrm{mm}$ internal diameter quarz tube) fluidized bed construction. Their findings on the manifestation of volatile flames are confirmed by the more extensive observations of the present work.

Since ignition of volatiles in the dense phase is prevented, the conversion rate of volatiles will be relatively low in this phase. Flames in bubbles, however, indicate a very rapid conversion at a 
(flame) temperature much higher than the bed temperature; bubbles can actually be hot spots.

\section{Manifestation of Volatile Flames}

Figure 5 illustrates the appearance of flames generated by coal particles of around $7 \mathrm{~mm}$ diameter initial size in a fluidized bed of highdensity alumina particles at $850^{\circ} \mathrm{C}$. Figure $5 \mathrm{a}$ shows a volatile flame history picture of 33 seconds along 11 lines of 3 seconds each. Open blocks on such a line represent the continuous occurrence of a bed surface flame. Bubble flame periods are indicated by the black blocks. As shown by Fig. 5 , flame periods up to 1.5 seconds are interrupted by time intervals of 2 seconds maximum.
Interruptions are caused by packets of bed particles extinguishing the flame, and possibly by discontinuities in the volatiles escape. When flames are present, their size is found to oscillate continually. The brown coal particle shown in Fig. 5a produces largest flames of at most $50 \mathrm{~mm}$ length. Flames of anthracite particles are always shorter than $25 \mathrm{~mm}$. The frequency at which flames arise in bubbles is relatively low; obviously the combustion of volatiles occurs mainly in the freeboard region as a consequence of the coal particles tendency to float on the bed surface during devolatilization. Comparing the last two lines (6 seconds) of the flame history diagrams, Fig. 5a only shows the presence of bed surface flames, in contrast with Fig. 5b, where in-bed

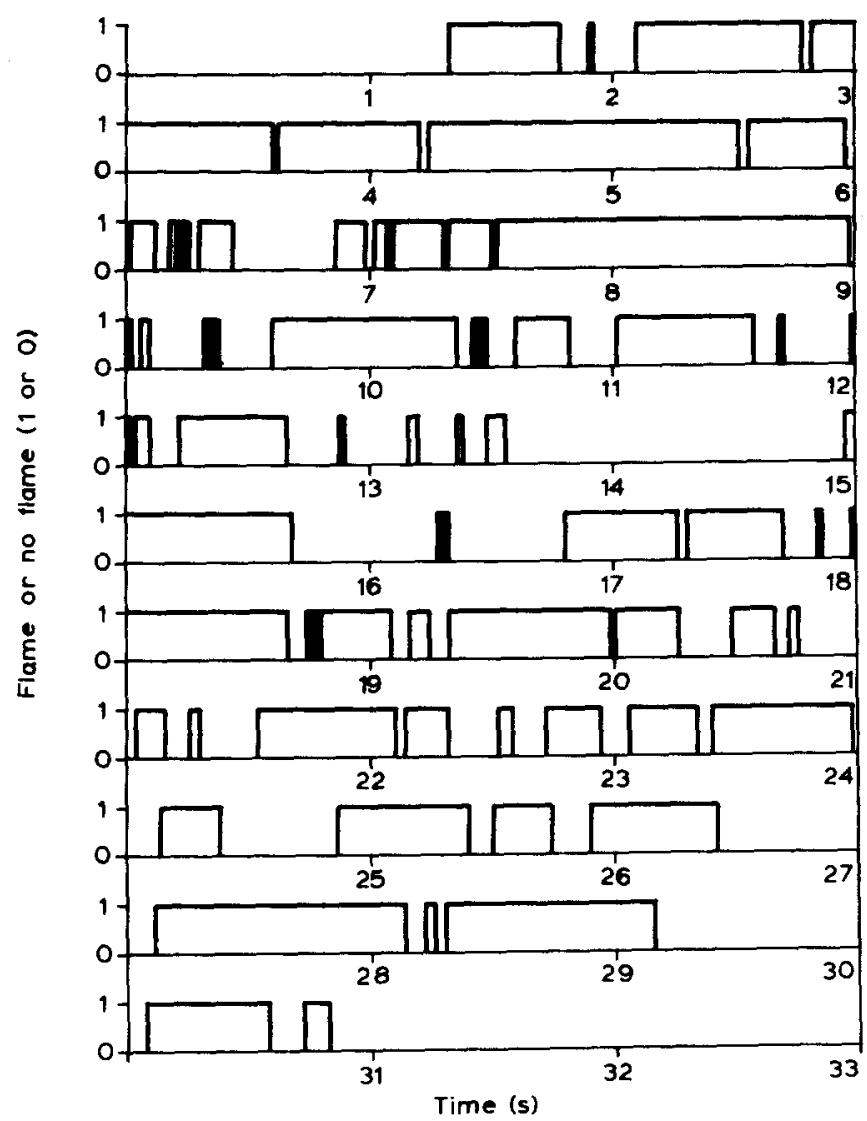

(a)

Fig. 5. Volatile flame histories: a, coal type $1, d=7.7 \mathrm{~mm}$; , coal type $3, d=6.7$ $\mathrm{mm}$; c, cosl type 4, $d=7.2 \mathrm{~mm}$. Bed material: high-density alumina, $T_{b}=850^{\circ} \mathrm{C} ; U$ $=0.44 \mathrm{~m} / \mathrm{s} ; X_{0_{2}}=0.21$. Black: flame in bubble; open: flame on bed surface. 


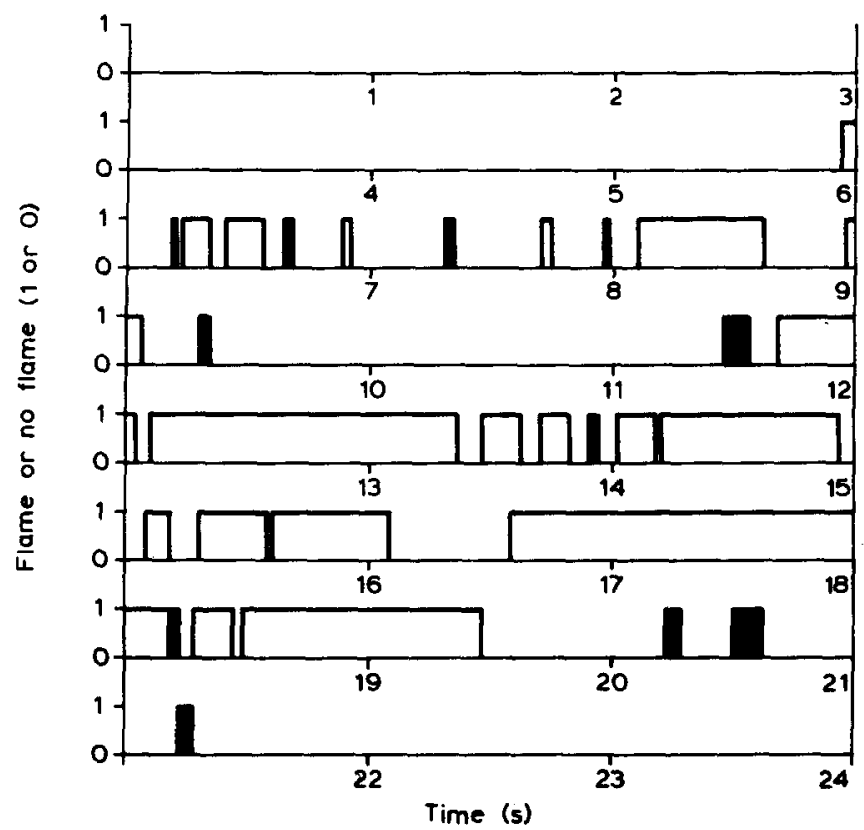

(b)

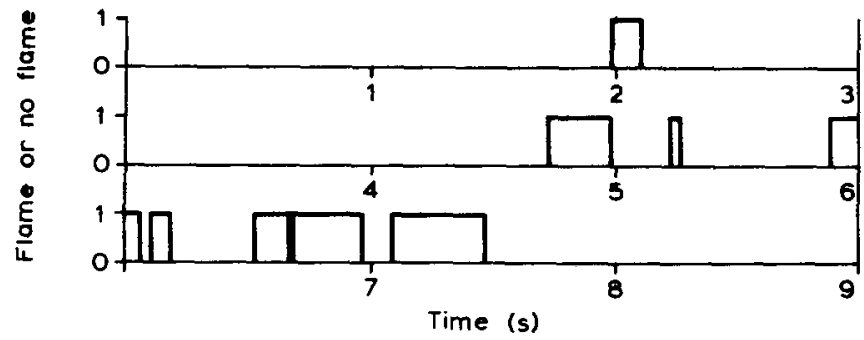

(c)

Fig. 5. (Continued).

bubble flames are still indicated. This difference of behavior during the last stage of devolatilization may indicate a better mixing for residual char particles of bituminous coal compared to those of brown coal.

At lower bed temperatures, flames may occur more or less incidentally. The evolution of volatiles, however, will proceed even though no further flames are observed. Below a certain bed temperature, $T_{v i}$, depending on coal type, ignition and subsequent combustion of volatiles no longer occur.

\section{Char Ignition}

Char ignition of coal particles starts as a single glowing spot at its external surface, which gradu- ally extends within a few seconds until the whole particle is glowing. The time period from the introduction of a coal particle into the fluidized bed until the moment at which a glowing spot arises and persists at the coal particle surface is called the char ignition delay time. Residual char particles burn steadily at a temperature that is substantially higher than the temperature of the surrounding bed as a consequence of the balance between heat generation by the combustion reaction and heat loss to the dense phase of the fluidized bed. (In a previous paper [4], the present authors showed how to calculate the temperature difference from proper mass and heat transfer data $[14,23]$. Differences up to $300^{\circ} \mathrm{C}$ are possible [4, 20].) Provisionally visible glowing was conceived 
a)

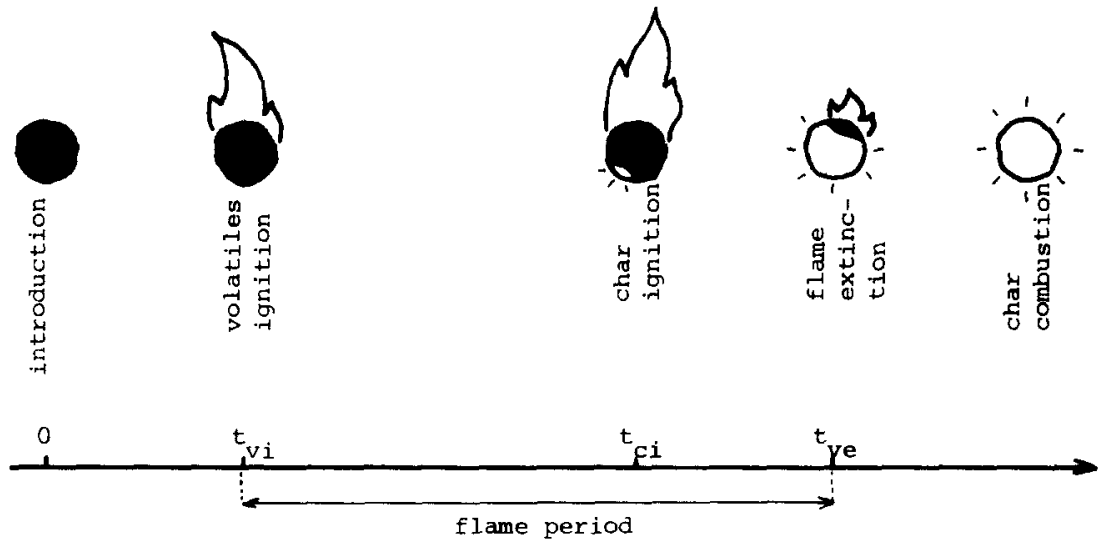

b)

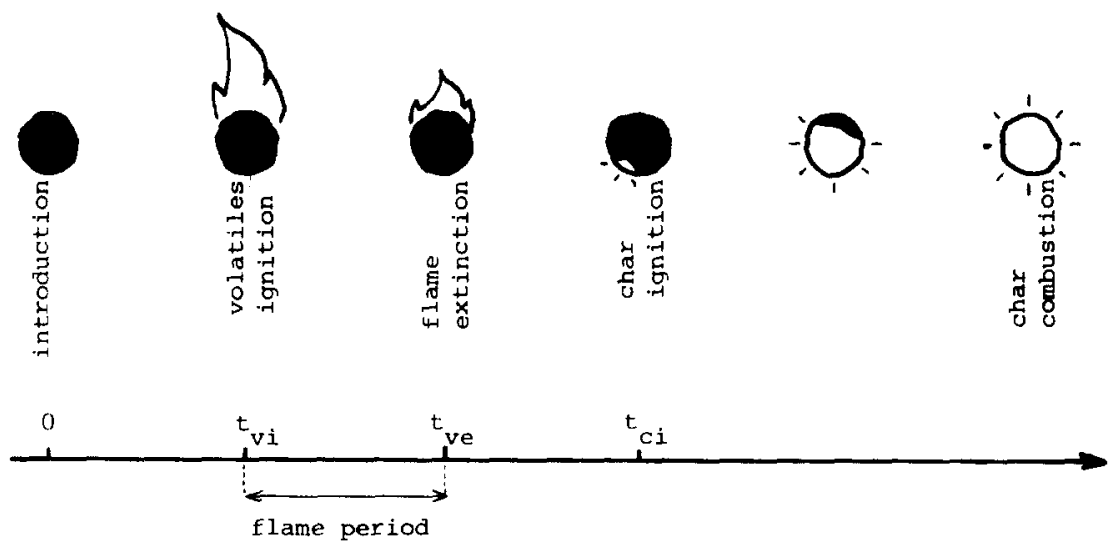

c)
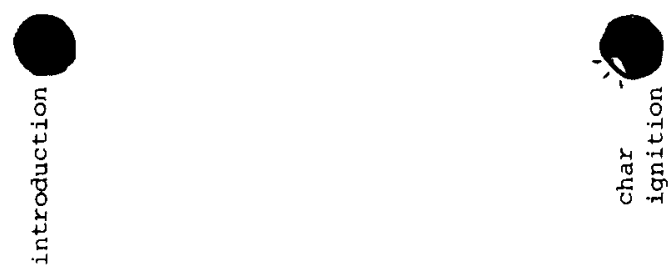

$-$

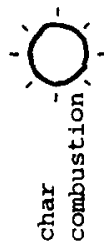

0 tci

Fig. 6. Sketch of events that happen to the coal particle from the moment of its introduction into the hot fluidized bed (coal particle fracture and tar release are not considered in this figure). a, coal type 2; b, coal type 3; c, $T_{b}<T_{v i}$.

as the appropriate indication of the burning char particle's excess temperature and are used here to determine the ignition point. Figure $6 \mathrm{a}, \mathrm{b}$ illustrates schematically the possibilities for char ignition at bed temperatures above $T_{v i}$, that is, during (as observed for coal type 2 particles) and beyond (coal type 3) the flame period. At low bed temperatures $T_{b}<T_{v i}$, when flames of volatiles are absent, char ignition is still possible (Fig. 6c). It has been observed that the bed temperature strongly influences the char ignition delay of coal particles: the delay increases drastically with 
decreasing bed temperature. Below a certain critical value of the bed temperature, which will be called the char ignition temperature, $T_{c i}$, no ignition delay can be determined since visible glowing of coal particles is no longer observed. Figure 7 further elucidates the meaning of various time and temperature parameters introduced in this study as it qualitatively illustrates the effect of the bed temperature on the ignition delay times of volatiles and char as well as on the flame extinction time. The course of the curves is based on results of measurements given in the next subsection (see Fig. 9).

\section{Measurements}

The results of measurements for coal type 3 are presented in Table 2. These measurements are also meant to show the reproducibility of the experiments with single coal particles and the different results obtained by the use of batches. Experimen- tal data reported in this section represent mean values of three identical experiments with similar coal particles. The use of batches instead of single coal particles is shown to cause overestimation of the flame extinction time. This can be seen by comparing the value of $t_{v e}$ obtained for a batch of 35 coal particles with the averaged $t_{v e}$ value from eight single particle experiments (14.1 versus 10.6 seconds).

\section{Volatiles Ignition Delay $\boldsymbol{t}_{\boldsymbol{v} i}$}

The time from the introduction of a coal particle into the fluidized bed until the first appearance of a volatile flame is called the volatiles ignition delay $t_{v i}$. This delay is only a few seconds at a bed temperature of $850^{\circ} \mathrm{C}$ for coal type 3 particles (see Table 2). Table 3 shows for coal type 2 that the ignition delay increases with decreasing bed temperature, which can be understood while realizing that the coal particle heating rate is directly proportional to the bed temperature. It can also be

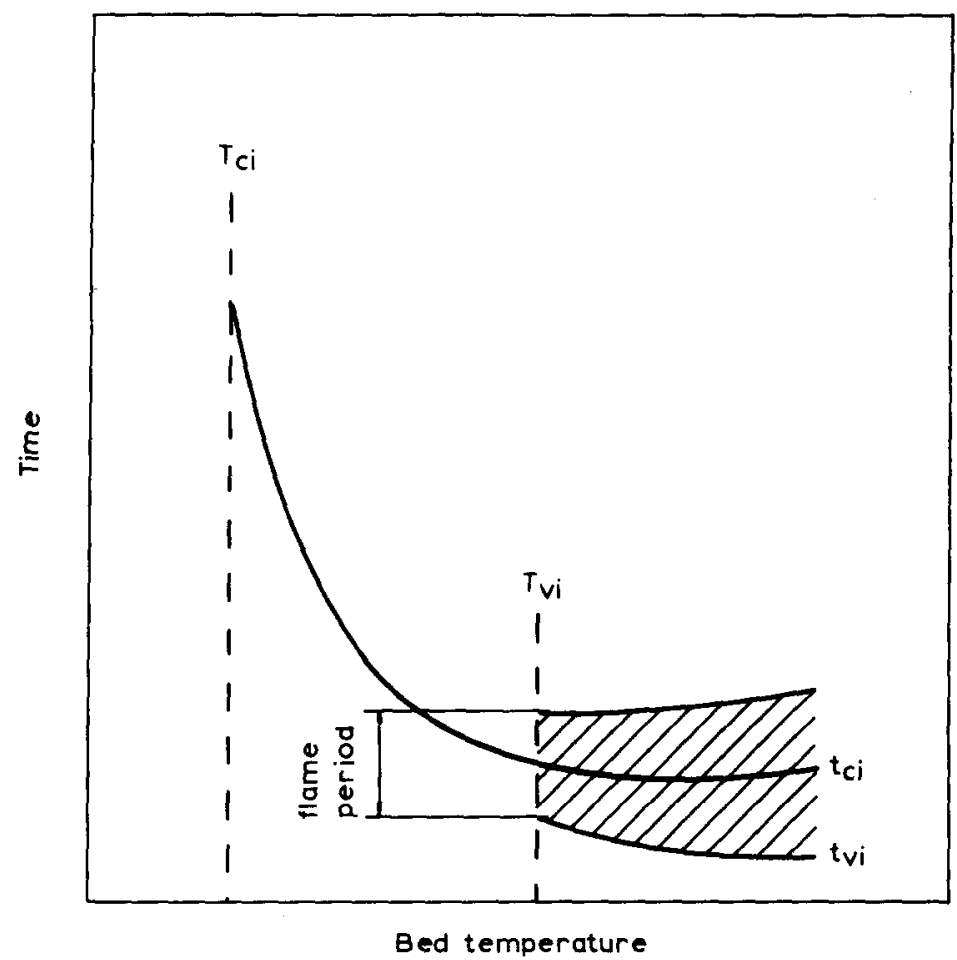

Fig. 7. Qualitative illustration of ignition phenomena in relation to the bed temperature. $t_{v i}$, ignition delay of volatiles; $t_{v e}$, flame extinction time; $t_{c i}$, ignition delay of char; $T_{v i}$, ignition temperature of volatiles; $T_{c i}$, ignition temperature of char. 
TABLE 2

Volatiles Ignition and Extinction Time, the Corresponding Flame Period, and Char Ignition Delay for Eight Single Coal Particles and a Batch of 35 Particles Under the Same Conditions

\begin{tabular}{ccccc}
\hline Sample & $t_{v i}(\mathrm{~s})$ & $t_{v e}(\mathrm{~s})$ & Flame Period $(\mathrm{s})$ & $t_{c i}(\mathrm{~s})$ \\
\hline 1 & 3.6 & 10.8 & 7.2 & 16.2 \\
2 & 4.8 & 9.0 & 4.2 & 14.4 \\
3 & 1.8 & 11.4 & 9.6 & 19.2 \\
4 & 4.8 & 10.8 & 6.0 & 14.4 \\
5 & 3.0 & 10.8 & 7.8 & 16.2 \\
6 & 3.0 & 10.8 & 7.8 & 12.0 \\
7 & 2.4 & 10.6 & 8.4 & 18.6 \\
8 & 2.4 & 10.6 & 7.4 & 12.6 \\
Mean Values & 3.2 & 10.6 & 12.0 & 15.5 \\
Batch & 2.1 & 14.1 & 12.0 & - \\
\hline
\end{tabular}

Bed material: low-density alumina, $T_{b}=850^{\circ} \mathrm{C} ; U_{f}=0.346 \mathrm{~m} / \mathrm{s} ; X_{0_{2}}=0.21 ;$ coal type $3 ; d=4.7 \mathrm{~mm}$.

\section{TABLE 3}

The Influence of Bed Temperature, Coal Moisture Contents, and Initial Particle Size on Ignition/Extinction Time and Flame Period

\begin{tabular}{|c|c|c|c|c|c|c|}
\hline$T_{b}\left({ }^{\circ} \mathrm{C}\right)$ & Coal Type & $d(\mathrm{~mm})$ & $t_{v i}(\mathrm{~s})$ & Flame Period (s) & $t_{v e}(\mathrm{~s})$ & $t_{c i}(\mathbf{s})$ \\
\hline 400 & $\begin{array}{l}2 \\
2 \\
2^{*}\end{array}$ & $\begin{array}{l}4.7 \\
8.6 \\
9.3\end{array}$ & $\begin{array}{l}- \\
-\end{array}$ & $\begin{array}{l}- \\
- \\
-\end{array}$ & $\begin{array}{l}- \\
-\end{array}$ & $\begin{array}{r}55.6 \\
94.2 \\
147.6\end{array}$ \\
\hline 500 & $\begin{array}{l}2 \\
2 \\
2^{*}\end{array}$ & $\begin{array}{l}4.7 \\
8.6 \\
9.3\end{array}$ & $\begin{array}{l}- \\
-\end{array}$ & $\begin{array}{l}- \\
-\end{array}$ & $\frac{-}{-}$ & $\begin{array}{l}21.2 \\
55.0 \\
68.4\end{array}$ \\
\hline 600 & $\begin{array}{l}2 \\
2 \\
2^{*}\end{array}$ & $\begin{array}{l}4.7 \\
8.6 \\
9.3\end{array}$ & $\begin{array}{l}- \\
-\end{array}$ & $\frac{-}{-}$ & $\begin{array}{l}- \\
-\end{array}$ & $\begin{array}{l}14.6 \\
16.2 \\
70.0\end{array}$ \\
\hline 680 & $\begin{array}{l}2 \\
2 \\
2^{*}\end{array}$ & $\begin{array}{l}4.7 \\
8.6 \\
9.3\end{array}$ & $\begin{array}{r}9.0 \\
17.6 \\
45.8\end{array}$ & $\begin{array}{r}7.2 \\
22.6 \\
26.8\end{array}$ & $\begin{array}{l}16.2 \\
40.2 \\
72.6\end{array}$ & $\begin{array}{l}12.5 \\
20.2 \\
34.2\end{array}$ \\
\hline 750 & $\begin{array}{l}2 \\
2 \\
2^{*}\end{array}$ & $\begin{array}{l}4.7 \\
8.6 \\
9.3\end{array}$ & $\begin{array}{r}2.8 \\
3.3 \\
19.2\end{array}$ & $\begin{array}{l}11.2 \\
43.2 \\
48.4\end{array}$ & $\begin{array}{l}14.0 \\
46.5 \\
67.6\end{array}$ & $\begin{array}{l}17.0 \\
26.4 \\
58.8\end{array}$ \\
\hline 850 & $\begin{array}{l}2 \\
2 \\
2^{*} \\
3\end{array}$ & $\begin{array}{l}4.7 \\
8.6 \\
9.3 \\
4.7\end{array}$ & $\begin{array}{r}1.2 \\
2.6 \\
10.9 \\
3.2\end{array}$ & $\begin{array}{r}12.4 \\
32.3 \\
53.9 \\
7.4\end{array}$ & $\begin{array}{l}13.6 \\
34.8 \\
64.8 \\
10.6\end{array}$ & $\begin{array}{l}13.8 \\
29.9 \\
37.4 \\
15.5\end{array}$ \\
\hline
\end{tabular}

Bed material: low-density alumina, $U=U_{m f}+0.25 \mathrm{~m} / \mathrm{s}, X_{0_{2}}=0.21$; coal type 2: air-dried-lignite; coal type 2*: wet lignite (as received). Before drying, coal type 2 samples had approximately the same weight as those of coal type $2 *$. 
seen from Table 3 that coal particles twice as large yield somewhat longer delay periods, and that wet coal particles (as received) cause the volatiles ignition delay to be several times larger than that for air-dried coal particles. The effect of moisture content is obvious since the production of combustible volatiles is retarded by the evaporation of water and is considerable heat effect [26].

\section{Volatiles Ignition Temperature $T_{v i}$}

For the conditions of the present experiments $\left(X_{0_{2}}\right.$ $=0.21$ ), a fluidized bed temperature of at least $680^{\circ} \mathrm{C}$ is required for the volatiles to ignite and produce flames, as described previously. The volatiles ignition temperature appears to increase slightly for lower oxygen mole fractions. For example, for $X_{0_{2}}=0.15$ flames of volatiles arose at $T_{b}>710^{\circ} \mathrm{C}$, and for $X_{0_{2}}=0.10$ at $T_{b}>$ $735^{\circ} \mathrm{C}$.

\section{Flame Period $t_{v e}-t_{v i}$}

At high bed temperatures, the period over which flames of volatiles can be seen (flame period) is supposed to be closely related to the total time of volatiles evolution, and hence to the production rate and the total yield of volatiles, because of favorable volatiles ignition conditions. These parameters, in turn, are determined by the heating rate and the final temperature of a devolatilizing coal particle. High heating rates, and thus high production rates of volatiles, occur for small coal particles and high bed temperatures (see Appendix); high volatiles product yields occur for large coal particles and high bed temperatures [12, 27]. The results shown in Table 3 are consistent with these considerations. At a certain bed temperature, the smaller coal particles $(\bar{d}=4.7 \mathrm{~mm})$ only produce a small amount of volatiles within a short time, resulting in a relatively short flame period of about 10 seconds. Larger coal particles $(d=8.6$ $\mathrm{mm}$ ), however, evolve a large quantity of gaseous products over quite a long period, as indicated by a flame period of around 30 seconds. As a result of increasing bed temperature, somewhat longer flame periods are indeed observed (largely according to the decrease in volatiles ignition delay).

A higher coal particle moisture content is shown (Table 3 ) to cause a marked extension of the flame period, next to the considerable increase in volatiles ignition delay. Apparently the moisture is not completely released previously and apart from the evolution of combustable volatiles. Simultaneous evaporation of water lowers the production rate of combustable volatiles because it reduces the coal particle heating rate.

No results can be presented about the influence of coal type or oxygen mole fraction on volatiles ignition delay and flame period because they have not yet been examined sufficiently. The effect of the fluidization velocity, however, was found to be negligible (Table 4).

\section{Flame Extinction Time $t_{\text {ve }}$}

As mentioned before, flame extinction times (volatiles burn-out times) have often been interpreted as the total devolatilization time. However, the evolution of volatiles may well proceed after a last flame has been observed, especially in fluidized beds, where volatile matter will not ignite as long as the coal particle stays in the emulsion phase. Direct comparison of devolatilization times, as determined by gas analysis, with observed flame extinction times from the same experiment, could provide information about the discrepancy. When the influence of the coal particle diameter on the devolatilization time for fluidized bed combustor conditions is considered, three regimes can be distinguished. First, when coal particles are very small ( $d \varangle 1 \mathrm{~mm}$ ), their devolatilization rate will be governed by the kinetics of chemical reactions. Devolatilization times are then independent of $d$. It should be realized here that external heat transfer controlled conditions for such small particles are not possible at fluidized bed combustor tempera-

\section{TABLE 4}

The Influence of Fluidization Velocity on Ignition Time and Flame Period

\begin{tabular}{cccc}
\hline$U(\mathrm{~m} / \mathrm{s})$ & $t_{v i}(\mathrm{~s})$ & Flame Period $(\mathrm{s})$ & $t_{\mathrm{ci}}(\mathrm{s})$ \\
\hline 0.346 & 3.5 & 7.4 & 15.8 \\
0.596 & 3.4 & 8.8 & 15.6
\end{tabular}

Bed material: low-density alumina, $T_{b}=850^{\circ} \mathrm{C} ; U_{m f}=$ $0.096 \mathrm{~m} / \mathrm{s} ; X_{0_{2}}=0.21$; coal type $3, d=4.7 \mathrm{~mm}$. 
tures; consequently, the situation of isolated particles in a stagnant conditions $(\mathrm{Nu}=2$ and $h \sim$ $d^{-1}$ ) [13], which would cause the devolatilization time to be proportional to $d^{2}$, will not occur. A second regime is reached upon entering the millimeter size range, as for the coal particles in the present study. The devolatilization rate will become controlled by heat transfer to and through the particle. The Appendix shows that, if the devolatilization time is taken to be proportional to $d^{n}$, the value of $n$ should now lay between 1.3 and 2. The value of $n=1.3$ corresponds to the extreme case of external heat transfer controlled devolatilization, while $n=2$ occurs for very large coal particles that are devolatilized under internal heat transfer controlled conditions. Experimental results shown in Table 3 indicate a value of $n$ around 1.7 for the observed flame extinction time. Provided the difference between devolatilization time and flame extinction time is small, this result may indeed lead to the conclusion that the devolatilization rate is controlled by both internal and external heat transfer.

\section{Char Ignition Delay $t_{c i}$}

The delay of char ignition is largely determined by the bed temperature (Fig. 8). Delay times $t_{c i}$ increase from around 20 seconds at $T_{b}=850^{\circ} \mathrm{C}$ to at least 100 seconds at $T_{b}=T_{c i}$. Absolute values further depend on the type of coal. At a relatively low bed temperature $\left(600^{\circ} \mathrm{C}\right)$, the char ignition delay of high-rank coals appears to be larger than of low-rank coals. This could be expected from the difference in reactivity with respect to the carbon/oxygen reaction. At a high bed temperature however, say $800^{\circ} \mathrm{C}$, low-rank coals show the largest ignition delay. The transition of behavior should be related to the process of

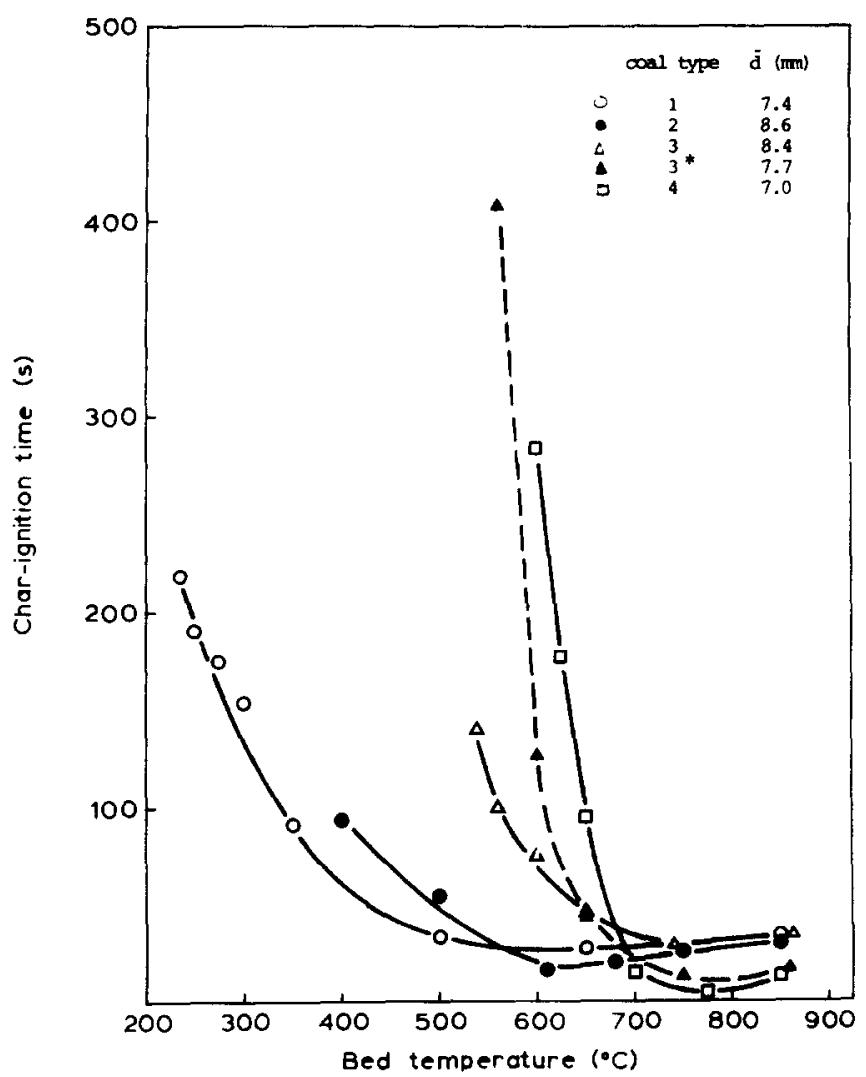

Fig. 8. Char ignition delay as a function of the bed temperature for five different coal types. Bed material: low-density alumina, $U_{f}=U_{m f}+0.25 \mathrm{~m} / \mathrm{s} ; X_{0_{2}}=0.21$. 
volatiles evolution. Whenever volatiles are released in a sufficiently continuous and uniform manner, and at a sufficiently high rate, oxygen is prevented from reaching the coal particle surface. At the same time the oxygen around the coal particle will be consumed by volatiles combustion rather than by the combustion of solid carboneous material. Obviously, at high bed temperatures all this is largely true for the high volatile, low-rank coals. At the low bed temperature, when combustion of volatiles is absent (no more flames), volatiles evolution may still be partially responsible for the char ignition delay. But its effect is then less important because delay times are so much longer.

The effect of volatiles evolution and combustion is furthermore illustrated in Fig. 8 by comparing results of coal types 3 and $3^{*}$, a bituminous coal and its derived char. The char particles were prepared separately by pyrolysis in a nitrogen fluidized bed at $850^{\circ} \mathrm{C}$. The relevant curves in Fig. 8 show that the difference between the ignition delay of coal 3 and $3^{*}$ particles changes sign at a bed temperature of approximately $650^{\circ} \mathrm{C}$. Below that temperature, solid ignition of the partially devolatilized coal particle occurs sooner than that of the volatiles free char particle. Above $T_{b}=650^{\circ} \mathrm{C}$, however, the rapid devolatilization and subsequent combustion of volatiles hinders the ignition of coal (type 3 ) particles. Consequently, derived char (type $3^{*}$ ) particles then ignite earlier. Another explicit example is given in Fig. 9.
Results of measurements for coal type 2 are selected from Table 3. Volatiles ignition delay times, flame extinction times, and char ignition delay times are plotted against the bed temperature. For this case of coal type 2 (ignition and extinction according to the mechanism sketched in Fig. 6a) a minimum occurs in the curve for char ignition delay beyond which the delay increases again with the bed temperature. This also is supposed to be a consequence of the increased production and combustion of volatiles at higher bed temperatures, which together hinders oxygen from reaching the coal particle surface and leads to an extension of the char ignition delay period.

Smaller coal particles of course ignite sooner than larger ones. This effect of coal particle size on the char ignition delay can be recognized from Table 3 (coal type 2) and Fig. 10 and 11 (type 1 and 3 , respectively). Table 3 further shows the influence of moisture: the ignition delay of wet coal particles (type $2^{*}$ ) appears to be much longer than for the air-dried coal particles (type 2). As stated before, the heating rate, and thus the length of the devolatilization period, depends on the size of a coal particle and its moisture content. Consequently, the char ignition delay, which is affected by the volatiles evolution, will be shorter for the small and/or dried coal particles.

Fig. 12 shows the influence of the oxygen mole fraction for another coal type 3 sample. Decreasing $X_{0_{2}}$ from 0.25 to 0.05 causes a considerable increase in char ignition delay. The effect is

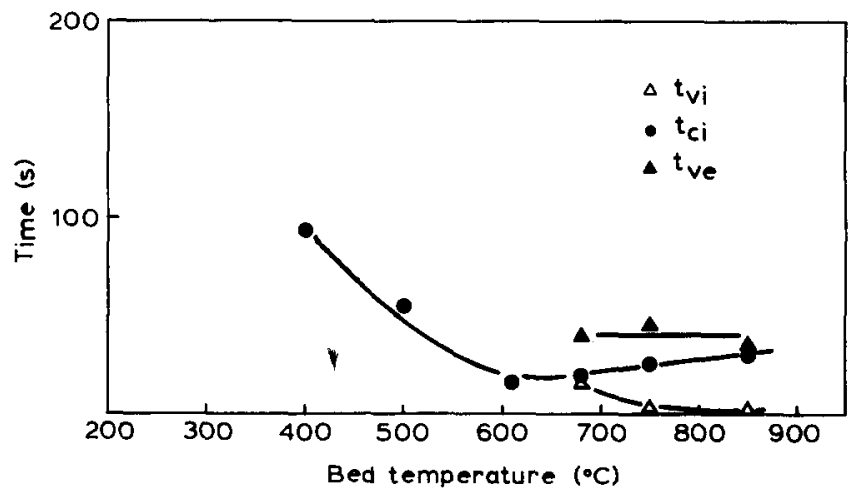

Fig. 9. Ignition delay of char and volatiles, and flame period as a function of the bed temperature. Bed material: low-density alumina, $U=U_{m f}+0.25 \mathrm{~m} / \mathrm{s} ; X_{0_{2}}=0.21$. Coal type $2, d=8.6 \mathrm{~mm}$. 


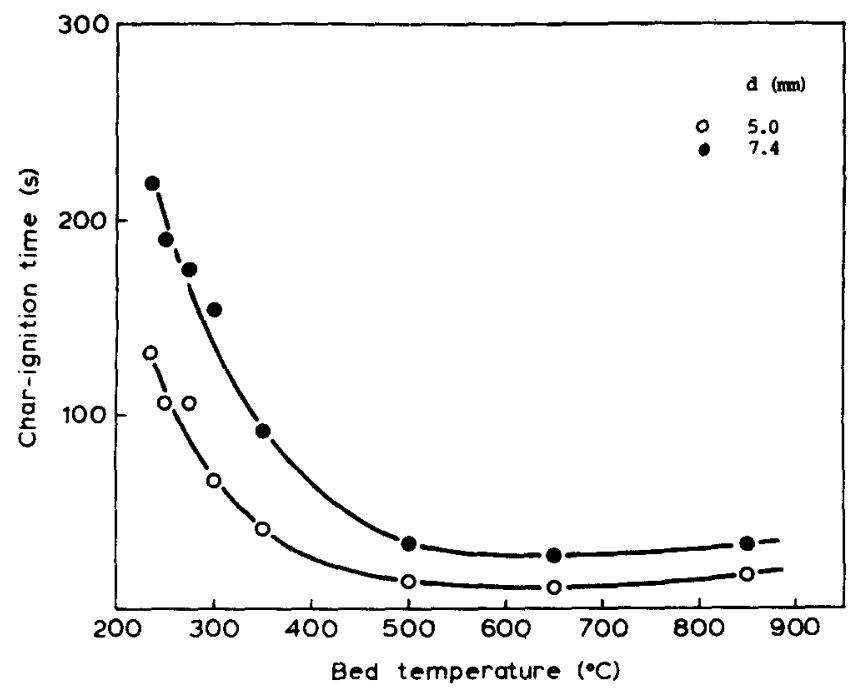

Fig. 10. Char ignition delay time of coal type 1 as a function of the bed temperature for two different initial coal particle sizes. Bed material: high-density alumina, $U=U_{m f}+$ $0.25 \mathrm{~m} / \mathrm{s} ; X_{0_{2}}=0.21$.

comparable with that of coal rank (see Fig. 8), with both being related to the coals reactivity for heterogeneous combustion. The factor by which the ignition delay is increased depends on the bed temperature and ranges from 2 at $T_{b}=850$ to 6 at $T_{b}=650^{\circ} \mathrm{C}$. Finally, the fluidization velocity was found not to affect the coal particles char ignition delay (Table 5).

\section{Char Ignition Temperature $T_{c i}$}

The lowest bed temperature required for char ignition of the various coal particles, as derived from Fig. 8, is first determined by the type of coal. These ignition temperatures have therefore been plotted in Fig. 13 against the reactivity index $V M /$ $C_{\text {fix }}$ (the ratio of the coal volatile matter and its

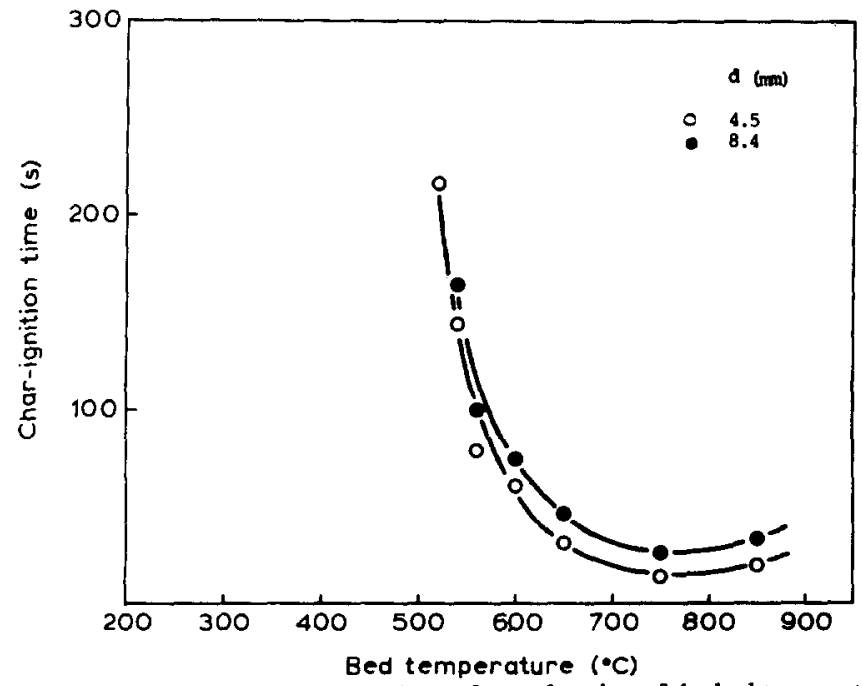

Fig. 11. Char ignition delay time of coal type 3 as a function of the bed temperature for two different initial coal particle sizes. Bed material: high-density alumina, $U=U_{m}+$ $0.25 \mathrm{~m} / \mathrm{s} ; X_{0_{2}}=0.21$. 


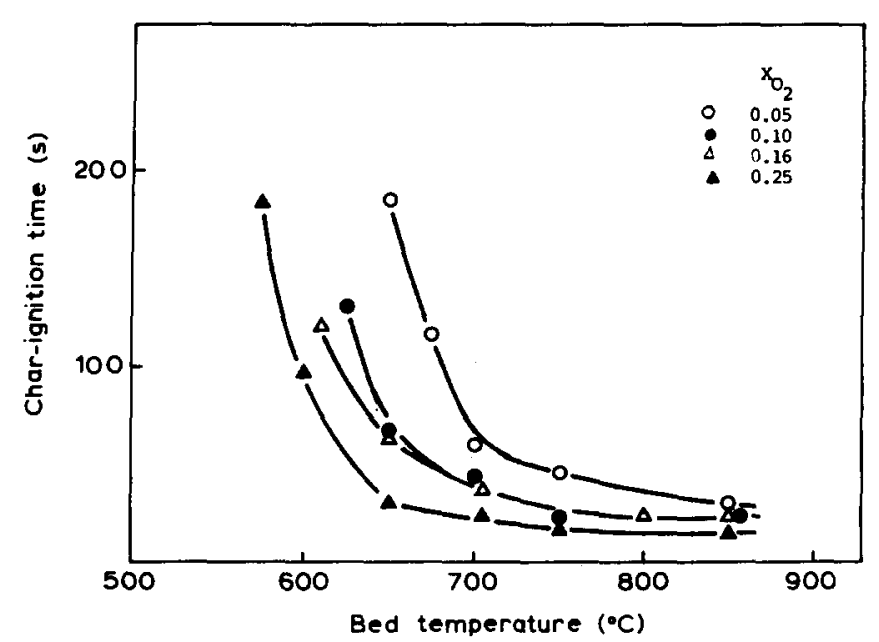

Fig. 12. Char ignition delay time as a function of the bed temperature for various oxygen mole fractions. Bed material: high-density alumina, $U=U_{m f}+0.25 \mathrm{~m} / \mathrm{s}$; coal type $3, d$ $=6.3 \mathrm{~mm}$.

fixed carbon content; see Table 1), a characteristic feature of coal rank and reactivity. Char ignition temperatures of coal particles in a fluidized bed are shown to decrease with increasing reactivity index from about 600 to $220^{\circ} \mathrm{C}$.

If reactivity is important, of course there must also be an effect of the oxygen mole fraction $\mathrm{X}_{\mathrm{O}_{2}}$ on the char ignition temperature. This indeed is true. Figure 14 is derived from the results of measurements with coal type 3 particles presented in Fig. 12. It shows an almost linear decrease of the char ignition temperature if the oxygen mole fraction is reduced from 0.25 to 0.05 , indicating a

\section{TABLE 5}

The Influence of Fluidization Velocity on Char-Ignition Delay

$T_{b}\left({ }^{\circ} \mathrm{C}\right) \quad t_{c i}(\mathrm{~s})$

\begin{tabular}{ccc} 
& $U=U_{m f}+0.25 \mathrm{~m} / \mathrm{s}$ & $U=U_{m f}+0.50 \mathrm{~m} / \mathrm{s}$ \\
490 & - & - \\
520 & 91 & 110 \\
550 & 49 & 47 \\
600 & 44 & 43 \\
650 & 32 & 23 \\
750 & 20 & 20 \\
850 & 19 & 22 \\
\hline
\end{tabular}

Bed material: high-density alumina, $U_{m}$ ranges from 0.175 $\mathrm{m} / \mathrm{s}$ at $T_{b}=850^{\circ} \mathrm{C}$ to $0.239 \mathrm{~m} / \mathrm{s}$ at $T_{b}=490^{\circ} \mathrm{C}$ (see Fig. 2); $X_{\mathrm{O}_{2}}=0.21$; coal type $3, d=6.6 \mathrm{~mm}$. first-order relationship between reactivity and $X_{0_{2}}$. As a last result of our measurements it is shown that neither the fluidization velocity (Table 5) nor the coal particle size (Fig. 10 and 11) affect the char ignition temperatures.

\section{DISCUSSION}

Ragland et al. [8] measured flame extinction times for coal particles suspended in a jet of heated gas. As in the present two-dimensional fluidized bed technique, this allows very accurate determination of flame extinction times. Despite certain differences in experimental conditions (mainly in external heat transfer), their results agree quite well with those of the present investigation, with respect to the relationship between flame extinction time and coal particle diameter as well. Compared to the values of $95 \%$ devolatilization times measured by Stubington and Sumaryono [9], however, there is a notable difference, which again confirms that flame extinction times are shorter than times for almost complete devolatilization. Pillai's [5] experimental flame extinction times for various coal types, batch-wise introduction into a fluidized bed at $T_{b}=875^{\circ} \mathrm{C}$ and $13 \%$ oxygen concentration in the supplied gas, are generally much larger (up to a factor of 3 ) than those of the present study. Apart from the conse- 


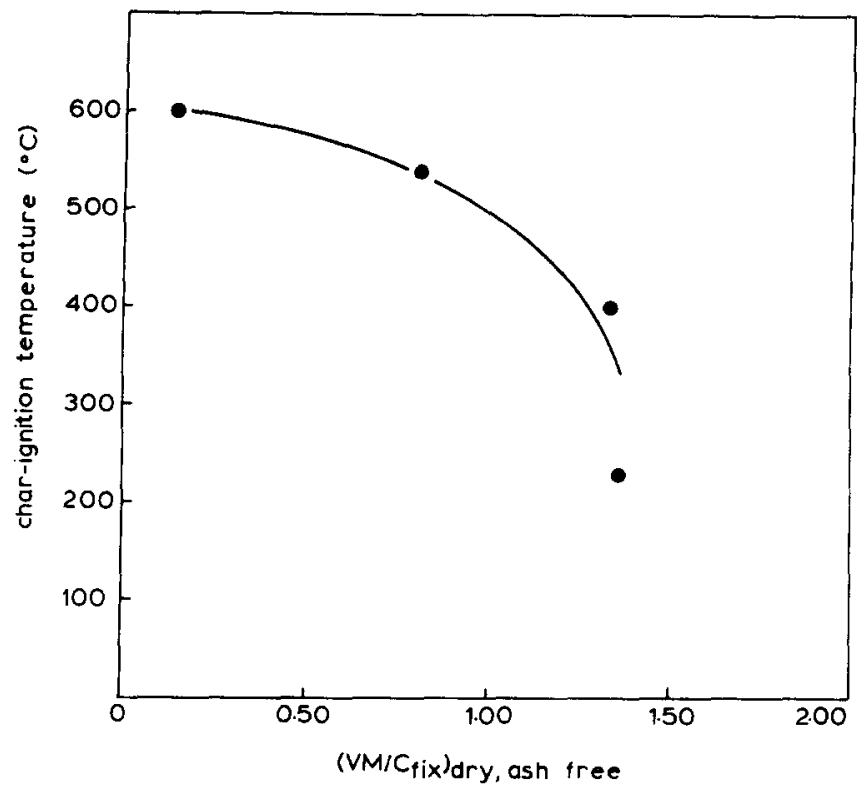

Fig. 13. Char ignition temperature in a fluidized bed as a function of the ratio of volatile matter over fixed carbon content (reactivity index).

quences of differences in experimental conditions, the use of batches instead of single coal particles may cause an overestimation of the flame extinction time. This is shown by the result of a special experiment (Table 2): the average flame extinction time of eight single coal particles ( 10.6 seconds) is clearly smaller than the value of $t_{v e}$ obtained for a batch of 35 particles (14.1 seconds). Obviously, the flame extinction time for a batch sample is determined by the last flames of just those few coal particles whose devolatilization period happens to be relatively long. Other phenomena that may interfere with the interpretation of results from batch experiments are the delay of coal particle

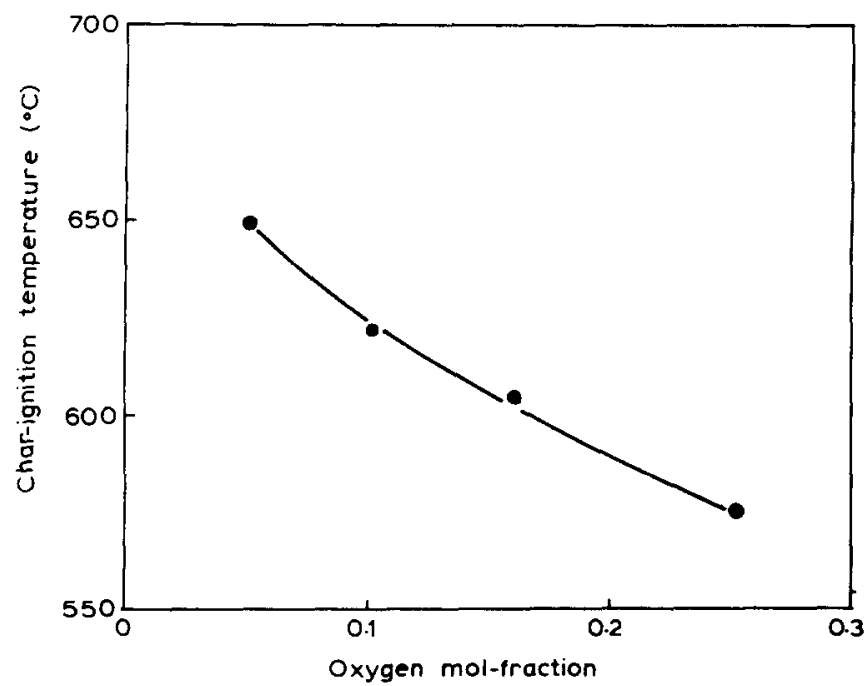

Fig. 14. Char ignition temperature as a function of the oxygen mole fraction. Bed material: high-density alumina, $U=U_{m f}+0.25 \mathrm{~m} / \mathrm{s}$; coal type $3, d=6.3 \mathrm{~mm}$. 
mixing with the bed upon introduction of a batch sample and the increased production of volatiles per unit of bed volume. Agarwal [13] found his single-particle model predictions of devolatilization times to agree well with the flame extinction times experimentally observed by Pillai [5] for batches. In view of the foregoing, the comparison is, however, considered questionable. The important modeling work done by Agarwal needs to be validated by more and better designed experiments. In the first instance, preference should be given to the study of single coal particle behavior. Together with burn-out times of volatiles, the essential input parameter of Agarwal's model (the coal particle residence time distribution over dense and bubble phase) should also be determined. The two-dimensional fluidized bed technique used in this study is well suited for such experiments.

Flame periods of the relatively large coal particles that have been studied here, and hence devolatilization times, appear to be much larger than the time required for mixing within the fluidized bed. Therefore, the existence of a volatile plume in an industrial fluidized bed combustor arising from a coal feed point at the bottom of the bed (underbed feeding) as proposed by Park et al. [3] is unlikely for such large coal particles. Especially if fines are present in the coal, oxygenlean regions near coal feed points cannot be excluded. However, the main quantity of volatiles will be released throughout the entire bed volume. In the conception of plug flow for the gas passing through a bed of well-mixed solids, the oxygen concentration is expected to decrease over the bed height, while there is no difference in concentration between dense and bubble phase (slow bubble regime). In-bed ignition and combustion of volatiles would then preferably occur within the many small bubbles of the oxygen-rich zone near the bottom plate.

Operating a fluidized bed combustor below the volatiles ignition temperature (at $T_{b}<T_{v i}$ ) (e.g., during start-up or turn-down procedures) is dangerous and inefficient. Unless precautionary measures have been taken, volatiles do not ignite and pass through bed and freeboard largely without being converted. If artificial ignition of volatiles is achieved (e.g. by the insert of pilot flame gas burners), the combustor can still be operated below $T_{v i}$. The operating temperature range is then restricted by the temperature of char ignition $T_{c i}$. For the exceptional case of feeding the combustor with a very reactive low-rank coal, operation at a bed temperature as low as $250^{\circ} \mathrm{C}$ might even be possible, a level at which hardly any volatiles are released from the coal particles. As a consequence of the relatively long delay periods in the temperature regime just above $T_{c i}$, the carbon content of the fluidized bed will be increased and the various time constants of control processes extended.

\section{CONCLUSION}

A small scale, two-dimensional fluidized bed construction made of quartz glass was placed in a furnace and operated at elevated temperatures. The facility has been used for direct observation of single coal particles $(4<d<9 \mathrm{~mm}$ diameter) after the introduction into a bed of alumina particles ( $0.6 \mathrm{~mm}$ diameter), fluidized by oxygen/ nitrogen mixtures of adjustable composition. In contrast with previous investigations, which were carried out in cylindrical beds, the coal particle could now be observed continuously along its complete trajectory through the bed. This paper shows that the study of single coal particle behavior is much improved by the use of a twodimensional fluidized bed; more accurate observations and measurements are possible.

Flames of volatiles never arise in the dense phase of the fluidized bed. But they do frequently appear within bubbles when the coal particle passes along or through them. Since coal particles tend to float on the bed surface during devolatilization, flames of volatiles may arise for a greater part at the bed surface.

At $21 \%$ oxygen concentration the bed temperature required for volatiles ignition was determined to be approximately $680^{\circ} \mathrm{C}$. The char ignition temperature of brown coal particles was found to be $220^{\circ} \mathrm{C}$, while for anthracite particles a bed temperature of at least $600^{\circ} \mathrm{C}$ was required. Both the volatiles and char ignition temperature increase if the oxygen concentration in the bed is decreased. 
Delay times of volatiles ignition (1-20 seconds) and char ignition (5-200 seconds) decrease at higher bed temperatures. In addition, char ignition delay times are influenced considerably by the type of coal: low-rank coals show a shorter ignition delay than high-rank coals at low bed temperatures and a larger delay for (approximately) $T_{b}>700^{\circ} \mathrm{C}$.

Typical values for flame extinction times are 15 seconds for a $4.7 \mathrm{~mm}$ and 40 seconds for a $8.6 \mathrm{~mm}$ diameter coal particle. The influence of the coal particle diameter can roughly be described with a $d^{1.7}$ proportionality. The effect of the bed temperature on the flame extinction time is small over the range $680<T_{b}<850^{\circ} \mathrm{C}$.

Wet coal particles (as received) show much longer volatiles and char ignition delay times, and also considerably increased flame extinction times, compared to air-dried coal particles.

Heating times of coal particles are estimated (see Appendix) while using the fluidized bed heat transfer data recently obtained by Prins et al. [14]. From a comparison with the values of the experimentally determined flame extinction time reported in this study, it is concluded that the rate of devolatilization is controlled by both heat transfer to and through the coal particle. The comparison of flame extinction times with results available in literature is very much obscured by the inconsistencies in experimental techniques and conditions. Finally, devolatilization times predicted by Agarwal's [13] single-particle model are much larger than the observed flame extinction times of the present study.

\section{APPENDIX}

A better understanding of the mechanism of coal particle devolatilization is obtained by considering the relevant heat balance plus boundary conditions:

$$
\begin{aligned}
& \frac{\partial T}{\partial t}=\frac{1}{r^{2}} \frac{\partial}{\partial r}\left(r^{2} \alpha \frac{\partial T}{\partial r}\right)+\Sigma \Delta H \\
& r=0: \frac{\partial T}{\partial r}=0 \\
& r=\frac{d}{2}: \frac{\partial T}{\partial r}=\frac{h}{\lambda}\left(T_{b}-T\right),
\end{aligned}
$$

where $\Sigma \Delta H$ represents the sum total of heat effects, such as the heat of pyrolysis, char combustion, and the evaporation of water. If this total heat effect is assumed to be negligible, and the thermal diffusivity $\alpha$ to be constant, the solution of the unsteady heat transport Eq. 1 is given by the socalled Heisler charts [28]. At these charts the center temperature, represented by $\left(T_{b}-T_{c}\right)$ / $\left(T_{b}-T_{o}\right)$, is plotted against the Fourier number $4 \alpha t / d^{2}$ for various values of the Biot number $h d /$ $2 \lambda$. The Biot number represents the ratio of the internal and external heat transfer resistance.

It is useful to estimate the shortest possible heating time from the Heisler chart solution for a comparison with the experimentally determined flame extinction time. If the estimated shortest possible heating times are of the same order of magnitude or larger than the observed flame extinction times, devolatilization must be heat transfer controlled.

The heating rate of the coal particle is not constant in time, but changes with the driving force. Consequently, the heat capacity $c_{p}$ and effective conductivity $\lambda$ of the coal also change in time because they depend on the (coal particle) temperature. The present simplified approach of estimating the shortest possible heating times relies on the use of constant values for $c_{p}$ and $\lambda$. But those heating times $t_{h}$, taken as the time required for the coal particle center temperature to reach a value according to a $90 \%$ reduction of the original driving force $\left(T_{b}-T_{c}\right) /\left(T_{b}-T_{o}\right)=$ 0.1 , are obtained while using relatively high values of $c_{p}$ and $\lambda$. They are calculated from Ref. [30] and [31], respectively, at the eventual coal particle center temperature $T_{c}\left(t_{h}\right)=T_{b}-0.1\left(T_{b}\right.$ - $T_{o}$ ). The heating time $t_{h}$ should therefore be considered as a conservative estimate; real heating times are presumably somewhat larger.

Besides $c_{p}$ and $\lambda$, another important parameter is the heat transfer coefficient $h$ for the heat flux from the fluidized bed to the coal particle. Proper information is available from the recent work done by Prins et al. [14]. Heat transfer coefficients have been shown to depend on the fluidizing velocity and have been found to pass through a maximum at a certain optimum value of $U$. The experimental conditions of the present study justify the assump- 
TABLE 6

Fluidized Bed Heating Times at $\left(T_{b}-T_{c}\right) /\left(T_{b}-T_{0}\right)=0.1$ for Various Sized Coal Particles Obtained from the Heisler [28] Chart Solutions of the Unsteady State Heat Transport Eq. 1

\begin{tabular}{rccccccc}
\hline$T_{b}\left({ }^{\circ} \mathrm{C}\right)$ & $c_{p}\left(\mathrm{~J} / \mathrm{kg}{ }^{\circ} \mathrm{C}\right)$ & $\lambda\left(\mathrm{J} / \mathrm{ms}^{\circ} \mathrm{C}\right)$ & $d(\mathrm{~mm})$ & $h_{2}\left(\mathrm{~J} / \mathrm{s} \mathrm{m}{ }^{\circ} \mathrm{C}\right)$ & $\mathrm{Bi}$ & $\mathrm{Fo}$ & $t_{h}(\mathrm{~s})$ \\
\hline \multirow{2}{*}{850} & 2800 & 1.2 & 2.25 & 740 & 0.73 & 1.3 & 4 \\
& & & 4.5 & 650 & 1.27 & 0.9 & 11 \\
750 & \multirow{2}{*}{2600} & 0.8 & 2.25 & 700 & 0.95 & 1.0 & 4 \\
& & & 4.5 & 610 & 1.66 & 0.7 & 12 \\
& & & 9.0 & 530 & 2.91 & 0.7 & 44 \\
650 & \multirow{2}{*}{2350} & 0.5 & 2.25 & 650 & 1.46 & 0.8 & 5 \\
& & & 4.5 & 570 & 2.55 & 0.6 & 15 \\
& & & 9.0 & 500 & 4.49 & 0.5 & 47 \\
\hline
\end{tabular}

Bed material: low-density alumina; $c_{p}$ and $\lambda$ are estimated from Ref. [30, 31]; heat-transfer coefficients are evaluated from Ref. [14].

tion of $h=h_{\max }$. Values of $h_{\max }$ are derived from the empirical correlation [14]:

$\mathrm{Nu}_{\max }=3.539 f_{T} \operatorname{Ar}^{n}\left(d / d_{p}\right)^{-0.26}$

$n=0.105\left(d / d_{p}\right)^{0.082}$

$f_{T}=0.844+0.0756\left(T_{b} / 273\right)$.

Calculated heating times as presented in the last column of Table 6 indeed are of the same order of magnitude as the observed flame extinction times reported in Table 6 . If flame extinction times are supposed to be almost the same as real devolatilization times, this would provide evidence for a heat transfer limited devolatilization mechanism. The internal resistance for heat transport is relatively important because Biot numbers, mentioned in Table 6, are generally larger than 1. For the large coal particles and high heating rates of the present experimental conditions, considerable temperature gradients arise within the coal particle upon heating to the fluidized bed temperature. Time-averaged coal particle heating rates appear to vary from about $12^{\circ} \mathrm{C} / \mathrm{s}$ for the largest to $120^{\circ} \mathrm{C} / \mathrm{s}$ for the smallest coal particle at $T_{b}=$ $650^{\circ} \mathrm{C}$, and similarly from 20 to $200^{\circ} \mathrm{C} / \mathrm{s}$ at $T_{b}=$ $850^{\circ} \mathrm{C}$.

It has often been suggested $[5,7,9,11,27]$ that the devolatilization time of a coal particle is proportional to $d^{2}$ under heat transfer controlled conditions. This indeed is true for internal heat transfer control. In case of external heat transfer control, the $d^{2}$ law only holds true for stagnant conditions around the coal particle $(\mathrm{Nu}=2)$. To illustrate these statements, the center temperature solutions [29] of Eq. 1 for the extreme cases of internal heat transfer control and external heat transfer control, respectively, are:

$$
\begin{aligned}
& \left(T_{b}-T_{c}\right) /\left(T_{b}-T_{0}\right) \\
& =\sum_{i=1}^{\infty} 2(-1)^{i+1} \\
& \quad \quad \times \exp [(-i \pi) \mathrm{Fo}] \text { for } \mathrm{Bi}>100 \\
& \left(T_{b}-T_{c}\right) /\left(T_{b}-T_{0}\right) \\
& =\exp [-3 \mathrm{BiFo}] \text { for } \mathrm{Bi}<0.1 .
\end{aligned}
$$

While realizing that Fo $=4 \alpha\left(t / d^{2}\right)$ and BiFo $=$ $\left(2 / \rho c_{p}\right)(t / d) h$, it can easily be seen that the time required for heating a coal particle up to a certain value of $\left(T_{b}-T_{c}\right) /\left(T_{b}-T_{o}\right)$ must be proportional to $d^{2}$ for internal heat transfer control (see Eq. 3), and also for external heat transfer control in case of stagnant conditions $\left(\mathrm{Nu}=2, h \sim d^{-1}\right.$, 
see Eq. 4). For fluidized bed conditions as in the present study, the empirical correlation of Prins et al. [14] predicts $h \sim d^{-0.26}$. Consequently the heat transfer controlled devolatilization time will be proportional to $d^{n}$, with $n$ between a value of 2 (internal heat transfer control) and 1.26 (external heat transfer control). A value of 1.6 that can be derived from the results of our heating time calculations (Table 6) corresponds to the case of combined internal and external heat transfer control, indicated also by the estimated Biot numbers. The experimentally determined flame extinction times (Table 3) show approximately the same relationship with the coal particle diameter: $t_{v e} \sim$ $d^{1.7}$.

The authors acknowledge the financial support of Shell Coal International Ltd., London.

\section{REFERENCES}

1. Pyle, D. L. Fluid. Combust. 2:6 (1975).

2. Stubington, J. F. J. Inst. Energy 53:191 (1980).

3. Park, D., Levenspiel, O., Fitzgerald, T. J. Fuel 60:295 (1981).

4. Prins, W., van Swaaij, W. P. M., in Fluidized Bed Combustion (Radovanovic, M, Ed.), Hemisphere Publishing Corp., Washington, D.C., 1986, p. 165.

5. Pillai, K. K. J. Inst. Energy 54:142 (1981).

6. Flint, W. L., Karmi, E. R. in Third International Fluidised Combustion Conference. Institute of Energy, London, 1984, p. 299.

7. La Nauze, R. D. Fuel 61:771 (1982).

8. Ragland, K. W., Jehn, T. C., Yang, J. T. in Eighteenth Symposium (International) on Combustion. The Combustion Institute, Pittsburgh, 1981, p. 1295.

9. Stubington, J. F., Sumaryono. Fuel 63:1013 (1984).

10. Agarwal, P. K., Genetti, W. E., Lee, Y. Y. Fuel 63:1157 (1984).

11. Anthony, D. B., Howard, J. B., Hottel, H. C., Meissner, H. P. in Fifteenth Symposium (International) on Combustion. The Combustion Institute, Pittsburgh, 1975 , p. 103.
12. Bliek, A. Ph.D. thesis, Twente University of Technology, The Netherlands, 1984.

13. Agarwal, P. K. Fuel 65:803 (1986).

14. Prins, W., Draijer, W., van Swaaij, W. P. M. in Heat and Mass Transfer in Fixed and Fluidized Beds (van Swaay, W. P. M., Afgan, N. H., Eds.), Hemisphere Publishing Corp., Washington D. C., 1986, p. 317.

15. Cowley, L. T., Roberts, P. Fluidised Combustion Conference, Capetown 1981, 2:443.

16. Dennis, J. S., Hayhurst, A. N., Mackley, I. G. in Nineteenth Symposium (International) on Combustion. The Combustion Institute, Pittsburgh, 1982, p. 1205.

17. Morris, J. P., Keairns, D. L. Fuel 58:465 (1979).

18. Jung, K. J., Stanmore, B. R. Fuel 59:74 (1980).

19. Pillai, K. K. J. Inst. Energy 55:132 (1982).

20. La Nauze, R. D. Chem. Eng. Res. Des. 63:3 (1985).

21. Basu. Trans. CSME 9:142 (1985).

22. Radovanovic, M., Prins, W., Siemons, R. V. Symposium on Use of Lignites in Thermoenergetics. Masinski Fakultet, Beograd, 1984 (in Yugoslavian).

23. Prins, W., Casteleyn, T. P., Drayer, W., van Swaaij, W. P. M. Chem. Engng. Sci. 40:481 (1985).

24. Masson, H. A. in Fluidized Bed Combustion (Radovanovic, M., Ed.), Hemisphere Publishing Corp., Washington, D.C., 1986, p. 184

25. de Kok, J. J., Nieuwesteeg, M. W. C. M. A., Van Swaaij, W. P. M. in Eighth International Conference on Fluidized Bed Combustion. Houston, TX, 1985, $1: 105$.

26. Agarwal, P. K., Genetti, W. E., Lee, Y. Y., Prasad, S. N. Fuel 63:1020 (1984).

27. Howard, J. B. in Chemistry of Coal Utilization, 2nd suppl. vol. (Elliot, M. A., Ed.), John Wiley and Sons, New York, 1981, p. 665.

28. Heisler, M. P. Trans. ASME 69:227 (1947).

29. Kozic, D., Vasiljevic, B., Bekavac, V. in Prirucnik za Termodinamiku Prostiranje Toplote, Iro Gradevinska Knjiga, Beograd, 1983, Ch. 8.

30. Badzioch, S., Gregory, D. R., Field, M. A. Fuel 43:267 (1964)

31. Melchior, E., Luther, H. Erdöl Kohle Erdgas Petrochemie 28:379 (1975).

Received 20 March 1986; revised 7 April 1988 